\title{
REDD Roses for a Green Lady - Target Setting for Deforestation in the Brazilian Amazon
}

\author{
Valny Giacomelli Sobrinho \\ Additional information is available at the end of the chapter \\ http://dx.doi.org/10.5772/57288
}

\section{Introduction}

In the lyrics written by Sid Tepper and Roy C. Bennett of a popular 1948 song, a broken-hearted guy, who had the day before argued with his girlfriend, rushed to the florist to buy some "red roses for a blue lady". His hope was that those pretty flowers could chase her blues away. In short, he wished some red flowers could compensate for the damage he had caused to his lover's heart.

Likewise, climate policy has recently ${ }^{1}$ come up with the REDD mechanism (Reduced Emissions from Deforestation and forest Degradation) to protect natural standing forests before they are damaged by deforestation or degradation. Within the REDD framework, carbon credits can be earned for deforestation avoidance, rather than as in forestry CDM (Clean Development Mechanism), for afforestation or reforestation.

Since deforestation gives off nearly one-fifth (1.6 Gt) of global carbon emissions [2], avoiding it is claimed to be the most effective and cheapest way of control. However, until recently deforestation avoidance had been kept out of international climate accords, mainly because of

1 The first time REDD came into the UNFCCC (United Nations Framework Convention on Climate Change) agenda was in 2005, when a mechanism for reducing deforestation and forest degradation was proposed by Papua New Guinea, Costa Rica and eight other countries. Two years earlier, Brazilian researchers had already come up with a similar tool backed by international payments for reduced deforestation. Between the Conference of the Parties (COP) in Bali, Indonesia, in 2007 (COP-13), and in Copenhagen, Denmark, in 2009 (COP-15), different REDD proposals emerged. As the scope of the mechanism was getting wider, its abbreviation was getting longer with the addition of "D's" and plus (+) signs. Chronologically, it started with RED - short for Reducing Emissions from Deforestation; next, it became REDD - when forest Degradation was added; then, it turned out to be REDD+ - so as to encompass conservation and enhancement of forest stocks through Sustainable Forest Management (SFM) techniques; at present, it has often been labelled REDD++, including reforestation and afforestation - that is, reforestation of non-forested areas [1]. Throughout this chapter, simply REDD will be employed, regardless of its several chronological meanings. However, afforestation and reforestation will be considered to fall into forestry-CDM - the branch of the Clean Development Mechanism suited to unnatural forests. 
the fear that credits supplied in return could flood carbon markets, thereby lowering the price of carbon credits [2]. But, with the closing, in 2012, of the first commitment period of the Kyoto Protocol (2008-2012), avoiding deforestation has been taken up as a post-2012 proposal for an international agreement that might bring in developing (non-Annex I) countries also to comply with emission targets.

Although the forest conservation feature of REDD means a step forward regarding carbon offsets from either energy or forestry-CDM [3], the credits arising from avoiding deforestation sound like roses offered as rewards for not causing damages to any "green lady" (forest). However, public incentive systems seldom pay people for not doing something - in the case of REDD, for not deforesting or not degrading. Hence, since a reward means a payment due for not doing something, it might encourage people to do what is already forbidden. In addition, it could make room for compensation seekers, whose anti-social and imprudent behaviour would otherwise have been inhibited by moral or legal censure [4].

Anyway, such a reward largely rests upon the creation of a market for REDD credits, in which Payments for Ecosystem Services (PES) are made to landowners and users, to compensate them for keeping forests - which are worth more alive than dead. PES schemes are defined as voluntary, conditional transactions - the payment is only made if the service is delivered - with at least one seller, one buyer, and a well-defined environmental service [2]. However, none of these conditions are yet in place in most REDD countries: the commodity is hard to quantify, the sellers are not well defined, big buyers do not exist and the rules of the game are not well established [5].

Besides these practical hindrances, REDD architecture is not without ideological critiques. Polanyi's [6] followers have charged not only REDD with having a privatising and marketing nature, but also PES with allowing elites and large-scale commercial actors to profit from what is called "forest capitalism". The gist of the criticism is that the largest share of deforestation is carried out by larger and wealthier players than by the poor, who REDD notwithstanding claims to be the greatest beneficiaries of the payments for avoiding deforestation [5]. Thus, of course, the bulk of these reward payments is expected to go to the players whose monetary foregone benefits are the greatest, when deforestation is halted.

Another pitfall of REDD and PES is that they rely too much on financial support. Although forests are assigned a high value in public debate, the relatively low returns accruing to forest management are due to the many and diverse non-financial benefits that forests can provide [7]. Both global REDD regimes and national REDD strategies call for the provision of financial resources - in the form of compensation or incentive payments - to alter the political economy of commercial access to forest resources [2]. Yet, REDD finance hinges on political will, institutional settings and long bureaucratic chains to work properly [2], [5].

At the national level, REDD policies demand the removal of support and subsidies for companies or activities that increase the pressure towards forest conversion - agricultural expansion, destructive logging, settlement schemes, plantation and road development in forest areas [2]. At the international level, a large proportion of finance will need to come from developed countries. Therefore, the scale of such finance will depend on the political will 
within these countries [5]. Nevertheless, developed countries are not likely to transfer payments to fragile states, where long-term efforts would be required to create or reform institutions, strengthen governance processes and build capacity to deal with the new models of forest management underlying REDD policies [2].

In any event, disturbances of this sort rest not only upon the promise to serve different actors and interests, but also upon that to bridge the environment and development agendas. While this proposal sounds so appealing and distinct from past efforts in the forestry sector, it not only has turned REDD into a successful idea, but also made it move from single (carbon) to multiple objectives. Such a move, though, is now threatening and overshadowing the main characteristic of REDD, which comes down to large-scale funding and performance-based support. So far, the vast majority of both developed and developing countries lack concrete strategies on how to implement REDD. Therefore, REDD finance remains unresolved, because the cost of reducing emissions from deforestation also depends on the strategy chosen [5].

Arguably, new strategies must emphasise carbon-stock protection [2]. Many studies have indicated that, after wood production, carbon sequestration is the most valuable output from forests [7]. However, a conservation market (REDD credits) for forest protection should draw on a form of compensation for producing something additional (new carbon stored), rather than on a reward for "not doing something" (not deforesting or not degrading) [4]. To begin with, this is supposed to help the political economy of REDD build the argument for its public support [4], thus allaying the mistrust that lurks over it of rewarding the wealthiest forest users.

A further step towards that shift lies in emphasising a stock maintenance rather than an emissions avoidance approach. This turns carbon conservation strategies from output (performance) into input-driven ones. After all, forest sequestration of carbon emissions is primarily a matter of forestland availability rather than of emissions avoided. If forest stocks are maintained or even increased, they do not emit carbon, which is kept there. Although this might sound like a "twosides-of-the-same-coin" problem, the stock maintenance approach highlights the positive side of conservation - the stewardship of carbon stocks - whereas the emissions avoidance approach stresses its negative side - the discouragement or closure of activities causing emissions to rise in spite of delivering economic benefits. Quite often, the latter is seen as an unproductive strategy while the former might well evoke the production of some useful commodity.

The commodity at stake is carbon storage rather than money. Yet, REDD finance claims that economic and monetary incentives can, through price signals, alter the decisions of individual land users and compensate them for foregone benefits from not converting or degrading the forest [2]. Since carbon storage is increasingly needed, the demand for carbon credits is expected to go up, thereby generating finance for forest conservation [5]. At present, however, there is deep uncertainty as to whether and how a future international climate agreement would value carbon sequestration provided by forests. In addition, when standing forests compete with high-value agricultural and mining commodities, no one can ensure anymore whether and how REDD funding - particularly output, results-based finance - would be available in the future. So far, from current REDD finance, it is widely recognised that more 
money alone cannot solve the deforestation problem and that the expectations of more money can even make it worse [8].

As argued elsewhere [3], [9], [10], since the ascent of money in modern societies, a community's wealth now has two components: real goods, accumulated through real investments, and fiat or paper "goods", made of nothing. Unlike the former, the latter kind of wealth is not subject to the natural law of decrease, the entropy law. Whereas the accumulation of real goods, which hold use value, does meet physical limits, there is no limit at all to the accumulation of "virtual wealth" [10], used for exchange only [9]. So, in this world, where the substance is exchanged for the shadow, what determines the value of money is the amount of wealth people prefer to do without, and that is the same as the amount of credit they retain as money [10]. In monetary economies, the greater this "virtual wealth" is, the higher the price of the real goods it can afford; conversely, the smaller the former, the lower the latter ${ }^{2}$. It is puzzling how the protection of environmental goods and services should be commanded by such a virtual wealth rationale [3], [9].

In this regard, a non-monetary Bio-Economic model for carbon Sequestration by Forests (BESF) [3] is applied to a deforestation scenario taking place in the Brazilian "Legal Amazon" region (Amazônia Legal, Figure 1), to show how forest stocks can be prevented from being degraded. After all, if these stocks wither away, they will no longer be able to store carbon emissions. The model assumes that the growth of natural stocks follows an upper limited path. Therefore, if emissions from economic growth $(k)$ have to be taken in by standing natural forests, their stocks could not fall below a certain limit. Those forest storage and tree growth constraints cap emissions.

Building upon fishery and forest bio-economics, in the BESF model emitters play the catchers, whereas natural forests supply the catch - namely, the environmental service of emissions storage. But unlike in fishery and forest models, the "catch", in this case, is an input rather than an output. As emissions increase, so does the demand for their storage, and the supply of forest stocks goes down. Thus, forest stocks turn out to be priced biophysically rather than monetarily.

Such a biophysically set price is called the bio-economic exchange rate $(\varepsilon)$. Found by dynamic optimisation methods, it works as a shadow price measuring the shortage of the environmental input (carbon removal) on demand. At any given time, the more (less) this service is demanded, the less (more) of it is carried over into the future. However, the supply of current removal stocks varies across the carbon sinks. Such spatial differences, measured by the bio-diversity ratio $\lambda$, are called "exports" $(Z)$ of carbon removal to elsewhere and correspond to conservation

\footnotetext{
2 In monetary economics, this relationship is known as the "quantity theory of money". "The quantity theory is a mechanistic proposition strangely alien to the assumptions of rational maximising behaviour on which classical and neoclassical theories generally rely ... It ignores the effects of the returns to holding money on the amounts economic agents choose to hold ... Money holdings depend ... on the opportunity costs, the expected changes in the value of money and the real yields of other assets into which the same funds could be placed" [11]. Of course, these remarks follow a Keynesian theoretical tradition, within which money is thought to be an asset rather than a token of bank liabilities to current account holders. Taking money as liabilities dates back to the days when bank-notes were "promises to pay", handed over at once as a receipt to depositors who had voluntarily given up gold to the bank, which, in turn, promised to repay them on demand [10].
} 
loans (REDD credits) between carbon sinks. On the other hand, the provision of such an environmental service in the future is "imported" (borrowed) from the savings of removal stocks that happened in the past. Therefore, these transfers of carbon removal over time are called "imports" $(M)$ and are referred to as compensation loans (CDM offsets) between the sinks.

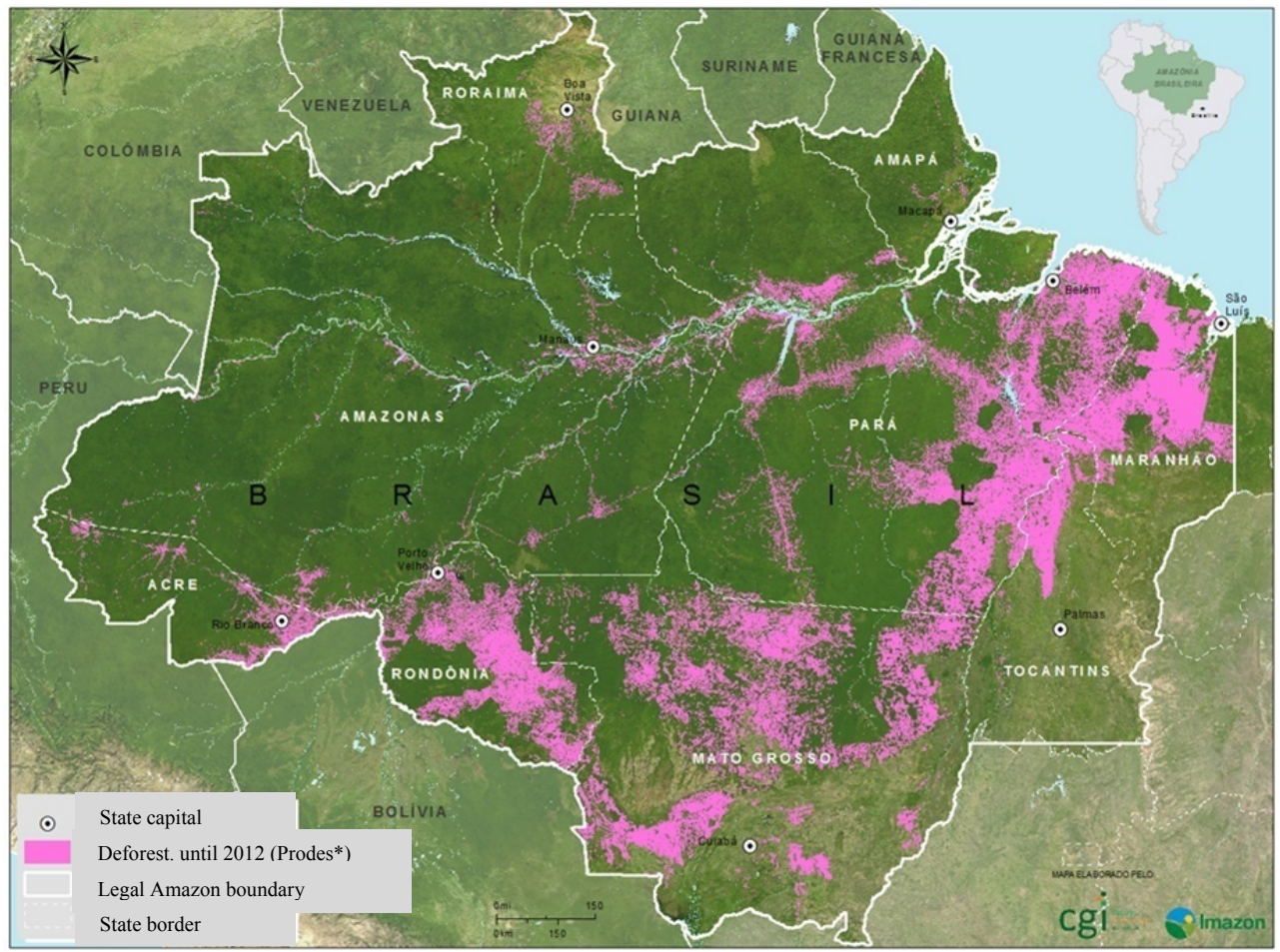

$\overline{\left({ }^{*}\right) \text { Prodes Project }}$ - Satellite-borne monitoring of the Brazilian Amazon Rainforest [23]; Source: [12]

Figure 1. Deforestation accumulated until 2012 in the Brazilian Legal Amazon

Whereas $Z$ means that the ecological burden of removing carbon emissions is "exported" to elsewhere, $M$ implies carrying the ecological burden within an economy's boundaries over time [3]. The former translates into an ecological credit $(0<\varepsilon<1)$ and the latter into an ecological $\operatorname{debt}(\varepsilon>1)$.

When conservation is low (high), compensation is supposed to decrease (increase), unless $\varepsilon$ depreciates (appreciates). Since $\varepsilon$ exchanges future carbon removal stocks $(M)$ for current ones $(Z)$, its rise (depreciation) means that $Z$ is relatively deteriorating, whereas its fall (appreciation) means that $Z$ is relatively increasing. Otherwise, for a given $\varepsilon, Z$ and $M$ vary positively with it (Figure 2.b). 
Just like bond markets are grounded in existing loan supply (savings) and demand (investment), removal loans for either carbon conservation or compensation are backed up by the biological growth of actual stocks (removal supply) of forest sinks set aside for curbing emissions from economic growth (removal demand). Forest-wide, $Z$ grows with $\lambda$, whose growth, in turn, causes $\varepsilon$ to fall (appreciate). On the other hand, the faster (slower) the speed $k$ of economic activity, the greater (smaller) the demand for $M$ and the depreciation (rise) of $\varepsilon$ should be. Hence, at this forestland level of aggregation, $\varepsilon$ is a negative function of the spatial distribution of carbon sinks $(\lambda)$ and a positive function of emissions given off by the growth of the economy over time $(k)$ (Figure 2.a).

The objective of probing these relationships is to demonstrate that the macro-scale determination of $\varepsilon$ (Figure 2.a) can help find: a) the optimal supply of conservation and compensation in the loan market for carbon removal (Figure 2.b); b) biophysically attainable deforestation targets at the micro-scale (Figure 2.c), according to the rates at which emissions from economic growth $(\ln k)$ are given off and the ratio of forest to deforested land - the bio-diversity ratio — varies $(\ln \lambda)$. This analysis will be carried out for three scenarios:

i. $\quad$ BAU (Business-As-Usual), in which $\ln k>\ln \lambda$;

ii. $\quad \operatorname{REDD}$, in which $\ln k<\ln \lambda$;

iii. $\quad \mathrm{CDM}$, in which $\ln k=\ln \lambda$.

To start with, the methodology sections will describe the BESF model, its geometry, basic assumptions, parameters, functions and variables. After that, empirical data on deforestation in Brazilian Amazonia will be used to account for the model equilibrium points - both at the micro and macro-scale. Finally, the aforementioned three scenarios will be assessed to determine, for either of them, how much forestland would have to be used for conservation (REDD) and for offsetting carbon emissions (CDM). According to this allocation, carbon sequestration provided by forests could be "paid" at its real, biophysical value, rather than according to the virtual monetary benefits such an environmental service is supposed to deliver.

\section{Research question and analytical framework}

The creation of a market for carbon is based on the assumption that monetary payments for carbon storage might make economic agents opt for forest conservation rather than forest conversion [4]. Although such payments might sound like a working solution, the heavier any forest-related decision falls back on them, the lighter it is supposed to lean on its biophysical and environmental footings. Thus, how should a market fit into turning this logic upsidedown? Put differently, how could ecosystem services, such as carbon sequestration, be priced biophysically rather than monetarily? What does that mean? How would it work?

The answers to whether prices can be equated with value or considered only indirect means of measuring values [13] rest upon the proposition that economic value should not be reduced to an ultimate one dimensional gauge, as held by the labour, utility and energy theories of 
value $^{3}$. Economic value should be thought of as not bearing a single substance out of which it should be drawn or within which it should be found. In a biophysical sense, value is limited to the degree to which an item contributes to an objective or condition in an ecosystem [16]. For instance, the biophysical value of a tree species could come from its contribution to controlling soil erosion in steeply sloped areas [16]. Elsewhere, the same tree species might be worth for, say, sequestering carbon. So, although the tree species has not changed, the substance or content from which its value is drawn has.

Furthermore, just like man cannot reach too deep into the material microcosm [13], he is likely unable to search too deeply for the one and only source of economic value. According to the Heisenberg principle of indeterminacy in quantum physics, and given the high complexity of microstructures, the probability of, say, building a living cell from scratch is extremely small [13]. By the same token, the probability of drawing economic value out of a single underlying source is very low.

Within the economy's biophysical realms, useful goods and services should be valued by their usefulness ${ }^{4}$ rather than by their exchange properties. What is meant by "usefulness" builds on Daly's [18] notion of ultimate efficiency, defined as the ratio of service to throughput. The services yielded by the stocks of artefacts are the ultimate benefit of economic activity. The throughput is the inevitable cost of maintaining the stocks of people and artefacts. Thus, in the

\begin{abstract}
3 Dating back to classical times, the labour theory of value paradoxically stated that only when land (natural resources) is (are) running out is the maximum value reached. Therefore, any natural resource that gets into the market and thus acquires exchange value is dying out or close to extinction. So, exchange value lays bare that there is less of that natural resource than there was when it held no value at all! Later on, the neoclassical utility theory displaced the economic value to an even odder container: consumption. In the "utility world", the economic value was placed in the individual preferences for commodities. As preferences were a subjective matter, the economic value then turned out to rest upon the abstract basis of utility. From then on, the economic analysis has been cut off from its biophysical roots [14]. But as early as 1883, S. Podolinsky pioneered the idea of associating energy with value, as claimed by energy theories of value. These theories aimed at substituting energy for money as the only source of value. However, money is not particularly correlated with energy content, because there is no direct equivalence between low entropy and economic value [13][15]. For instance, the monetary value per unit energy content of a diamond is extremely large compared to the monetary value per unit energy content of a lump of coal. Nonetheless, if all indirect energy flows were to be tracked down and accounted for, the discrepancy between diamonds and coal might not be so great [15]. By and large, economists have rebutted these energy evaluation methods because of the fear that economics might end up turning into a branch of thermodynamics [14]. Furthermore, as Georgescu-Roegen [13] once pointed out, the economic process has only two flows: an input flow of low entropy and an output flow of high entropy, namely, waste. If the balance sheet of value should be set on the basis of these inputs and outputs, one "would arrive at the absurd conclusion that the value of the low entropy flow on which the maintenance of life itself depends is equal to the value of the flow of waste, that is, zero" (p. 284). This paradox only vanishes by acknowledging that the true "product" of the economic process is not a material flow, but a psychic flux - the enjoyment of life. Thus, the economic value has both psychic (neoclassical) and physical (classical) roots. An entropy-oriented, energy theory of value would only account for the supply side of the process and neglect the corresponding demand side [9]. That is why the proposition of a shadow price for natural resource inputs, on one hand, and for the waste sinking capacity of the environment, on the other, results from an economic rather than from an energy theory of value [14].
\end{abstract}

4 Although nature might well have other values - existence and bequeath - than use ones, non-use values are harder to estimate. Obviously, the use value is the one arising from the real - direct, indirect or optional - use of a given resource, whether in the present or in the future. On the other hand, the existence value is simply related to the existence of specific riches. The bequeath value measures the benefit that any individual obtains from knowing that, in the future, other people will also be able to benefit from the resource they have been left [17]. First and foremost, both non-use values essentially depend on estimating the preferences of future generations, which is not that easy to foreshadow. Moreover, non-use values resemble very much the intrinsic value of nature, which was claimed by Deep Ecology followers. According to them, nature had to be preserved for itself, rather than for satisfying the well-being of present and future generations. The intrinsic value is fully separated from any use value, even in the future [14]. Once these non-use concepts are difficult to apply, environmental goods and services are taken up thereafter in their usefulness sense. 
final analysis, the stock of physical wealth is an accumulated flow of throughput, which is a cost to be minimised [18].

Likewise, if carbon removal is the service to be used, then it must be valued by the biophysical cost of delivering carbon removal stocks. Yet if not technically estimating price or value, a method that estimates costs should at least be a fairly good approximation to price and value, when markets are in equilibrium [16]. As known, whenever a commodity has a much higher value than its cost of production, its profits will be higher. The commodity will then be produced with increasing marginal costs until cost just equals price and profits are zero. The opposite happens when the commodity cost is much higher than its value. Since the commodity profits are lower, it will not be produced. The marginal costs then decrease until cost and price are equal.

As real markets are seldom in equilibrium, cost and price are expected to diverge, so that commodities could become overpriced or underpriced. The shadow price $\varepsilon=M \div Z$, calculated by the BESF model, is the biophysical sign of that distortion. It informs how far or close the growth rates of the economy's emissions (ln k) and of the forest stocks to remove them $(\ln \lambda)$ are from each other (Figure 2.a). As explained before, the greater $\lambda$ is, the larger $Z$ will be, which, ceteris paribus, makes $\varepsilon$ go down (appreciate); on the other hand, the greater $k$ is, the larger $M$ will be, which, ceteris paribus, makes $\varepsilon$ go up (depreciate). The optimal balance between $k$ and $\lambda$ defines not only $\varepsilon^{*}$, in Figure 2.a, but also the optimal level of carbon conservation $\left(Z^{*}\right)$ and compensation $\left(M^{*}\right)$, in Figure 2.b, as well as the optimal growth $\left(G\left(X_{t}\right)\right)$ of and demand $\left(h_{t}\right)$ for carbon removal stocks $\left(X_{t}\right)$, in Figure 2.c. Hence, any bio-economic distortion in carbon prices is communicated by the bio-economic exchange rate $\varepsilon$.

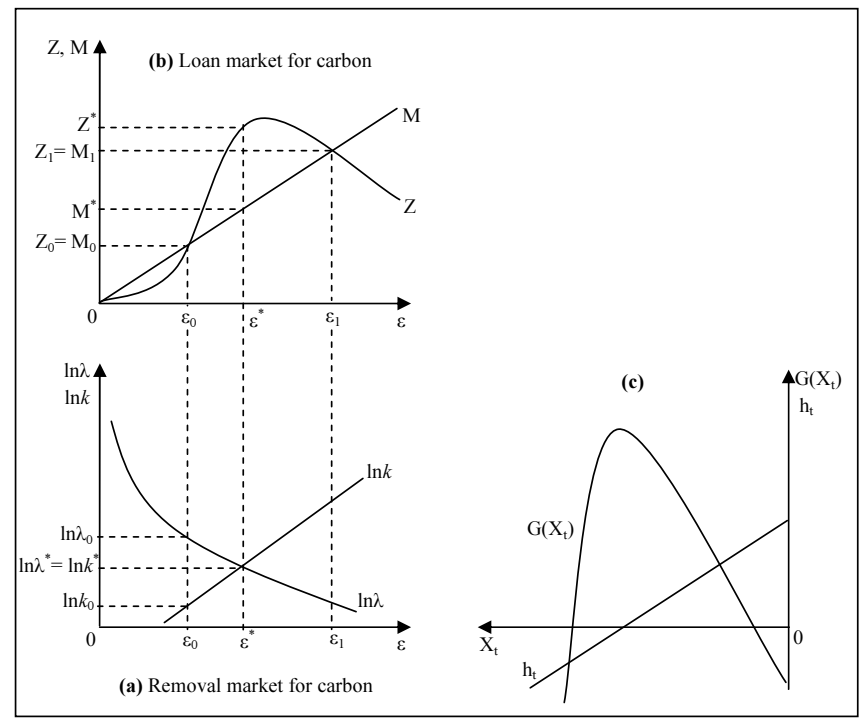

Figure 2. Loan and removal markets for carbon 
For instance, given the hypothetical functional forms shown in Figure 2, $\varepsilon^{*}$, found in Figure 2.a, requires carbon conservation $\left(Z^{*}\right)$ to be greater than carbon compensation $\left(M^{*}\right)$, in Figure 2.b. Similarly, as $\varepsilon^{*}$ was the outcome of a specific value taken on by $\lambda$ and $k$, this bio-diversity ratio $\left(\lambda^{*}\right)$ and economic growth rate $\left(k^{*}\right)$ will then be applied to yield the curves depicted by Figure 2.c. It is these curves that set optimal deforestation targets and rates if forestland is split into deforested $(\mathrm{u})$ and conserved $(\mathrm{v})$ patches.

\section{Model assumptions}

Figure 2.c draws on bio-economic models, such as forestry and fishery models, which are concerned with the age and size of their biomass stocks (trees and fish) [3][19]. As the growth of a forest depends on the age of its trees, forestry models consider the time at which the maximum biological growth - or Maximum Sustainable Yield (MSY) - will be reached. In contrast, since fish growth depends on the size instead of on the age of fish stocks, fishery models involve the stock size at which the Maximum Economic Yield (MEY) will be attained [3].

Despite their different biological and economic emphasis, both such models are concerned with the output (trees and fish) provided by the corresponding natural source (forests and oceans). Neither of them, though, cares about the input - environmental service - supplied by the natural sink upon which the corresponding resource stock grows. Therefore, in the BESF model, the biomass stock is an input rendering an environmental service (carbon removal), instead of an output yielding biological (MSY) and economic (MEY) gains [3].

In this case, the stock harvested $\left(\hat{h}_{t}\right)$ stands for the throughput of emissions removal - or the environmental cost of storing in the forest biomass the emissions given off by the production and consumption of the economy's output. Provided that emissions from economic growth have to be removed by natural standing forests, the supply of removal forest stocks $\left(G\left(X_{t}\right)\right)$ need to meet an upper boundary $\left(K_{h}\right)$ somewhere, since tree growth typically has an upper bound [3].

\section{Model parameters and variables}

Such an upper bound $\left(K_{h}\right)$ depends both on space $(\lambda)$ and time-related $(k)$ variables (Table 1 and Table 2). On one hand, $K_{h}$ is a function of $\lambda_{t}$ (Eq. (3)) - the spatial distribution of forest biomass $X_{t}$ (Eq. (1)), in GtC, between $j=1, \ldots, n$ conserved (v) and deforested (u) sinks at each time period $t=1, \ldots, m$, where $\mathbf{u}=\left(u_{1}, u_{2}, \ldots, u_{m}\right)=\left(x_{11}, x_{21}, \ldots, x_{m 1}\right) ; \mathbf{v}=\left(v_{1}, v_{2}, \ldots, v_{m}\right)=\left(x_{1 n}, x_{2 n}, \ldots\right.$, $\left.x_{m n}\right) ; \mathbf{u}<\mathbf{v} ; x_{t j}=$ carbon-equivalent emissions by sources at time $t$ to be stored (removed) by sink $j$. On the other hand, the distribution of forest biomass is highly affected by economic activity and the rate at which land-use changes take place. In other words, $\lambda_{t}$ depends on $k_{j}$ (Eq. (12)) - which measures emissions from deforestation or carbon emissions of sink $j$ given off by its economic growth over time. 
As time goes by, the ratio of energy changes $(\ln k)$ to land changes $(\ln \lambda)$, measured by $\varepsilon(E q$. (14)), indicates in each period how much emissions from economic growth can be removed by each hectare of forestland [20]. Whereas economic growth $(k)$ demands increasing removal of stocks, the supply of rising stocks is constrained by biophysical limits on growing and maintaining standing forests $(\lambda)$.

Building on standard bio-economic (forestry and fishery) models, it is assumed that such a biological growth constraint follows a logistic pattern [3]. So as to hook the economy to its natural strings, emission flows $\left(h_{t}\right)$ must be capped $\left(K_{h}\right)$ rather than the growth of removal forest stocks $\left(G\left(X_{t}\right)\right)$, which already are by nature. Capping emissions from deforestation, though, implies that, at some former time $T$, when deforestation was negligible, there was a maximum level of removal stocks, $X_{K}$, associated with that least emission release $\left(K_{h}\right)$.

\begin{tabular}{|c|c|c|c|c|c|}
\hline \multirow{2}{*}{$\begin{array}{c}t \text { periods } \\
\text { (emission sources) }\end{array}$} & \multicolumn{2}{|c|}{$\begin{array}{c}j=1, \ldots, 2 \\
\text { removal } \operatorname{sinks} s^{*}(\mathbf{u}<\mathbf{v})\end{array}$} & \multirow[t]{2}{*}{$x$} & \multirow[t]{2}{*}{ Z } & \multirow[t]{2}{*}{$\lambda$} \\
\hline & $\mathrm{u}$ & $\mathbf{v}$ & & & \\
\hline 1 & $x_{11}$ & $x_{12}$ & $X_{1}$ & $Z_{1}$ & $\lambda_{1}$ \\
\hline$\vdots$ & $\vdots$ & $\vdots$ & $\vdots$ & $\vdots$ & $\vdots$ \\
\hline$m$ & $x_{m 1}$ & $x_{m 2}$ & $X_{m}$ & $Z_{m}$ & $\lambda_{m}$ \\
\hline V & $V_{1}$ & $V_{2}$ & $V=X$ & $Z$ & $\lambda$ \\
\hline$M$ & $M_{1}$ & $M_{2}$ & $M$ & $\varepsilon$ & \\
\hline$k$ & $k_{1}$ & $k_{2}$ & k & & \\
\hline
\end{tabular}

$\left({ }^{*}\right) j=\mathbf{u}=$ the smallest carbon biomass stock sink or the deforested $\sin k ; j=\mathbf{v}=$ the largest carbon biomass stock sink or the conserved sink. It is required that $\varepsilon>0$, because, in biophysical terms, there cannot be a negative accountancy [10]. Therefore, so that $Z>0, j$ sinks must be displayed on an increasing biomass stock order. Likewise, so that $M>0, M_{j}=\mid$ $x_{m j}-x_{1 j} \mid$.

Source: [3]

Table 1. Algebraic emission-removal matrix

$$
\begin{gathered}
X_{t}=\sum_{j=1}^{n} x_{t j} \\
Z_{t}=v_{t}-u_{t}=x_{t n}-x_{t 1} \\
\lambda_{t}=v_{t} / u_{t}=x_{t n} / x_{t 1} \\
\lambda=1+\left(Z / V_{1}\right) \\
\ln \lambda=Z / V_{1} \\
V=\sum_{j=1}^{n} V_{j}
\end{gathered}
$$




\begin{tabular}{|c|c|c|c|}
\hline Dimension & Variable & Description & Equation \\
\hline \multirow{7}{*}{ Space } & $X_{t}$ & Total removal stock at time $t$ & (1) \\
\hline & $Z_{t}$ & $\begin{array}{l}\text { Exports, at time } t \text {, of removing services across the space and } j \\
\text { sinks }\end{array}$ & $(2)$ \\
\hline & $\lambda_{t}$ & $\begin{array}{l}\text { Bio-diversity ratio of deforested to conserved forestland at time } \\
t\end{array}$ & (3) \\
\hline & $\lambda$ & Source-sink system's bio-diversity ratio & $(4) a,(4) b$ \\
\hline & V & Total spatial bio-economic value of the $j$ removal sinks & (5) \\
\hline & M & Total spatial imports (across all sinks) & (6) \\
\hline & $\psi_{t}$ & ${ }^{\dagger}$ Biophysical overshoot rate at time $t$ & (7) \\
\hline \multirow{6}{*}{ Time } & $x$ & Total removal stock over time & (8) \\
\hline & Z & Total exports over time & (9) \\
\hline & $V_{j}$ & $\begin{array}{l}\text { Bio-economic value of sink } j \text { arising from its long-run supply of } \\
\text { biomass stocks for emission removal }\end{array}$ & $(10)$ \\
\hline & $M_{j}$ & Imports (loans) of removing services per $j$ sink through time & $(11)$ \\
\hline & $k_{j}$ & Deforestation rate at sink $j$ & $(12)$ \\
\hline & k & Source-sink system's deforestation rate & (13)a, (13)b, (13)c \\
\hline \multirow{2}{*}{ Space-time } & $\varepsilon$ & Bio-economic exchange rate & (14) \\
\hline & $\psi$ & Long-run overshoot rate & (15) \\
\hline
\end{tabular}

(†) $k_{t}=$ variable $k$ (Eqs. (13)a-c) at time $t ; k^{*}=$ optimal value for $k$.

Source: [3]

Table 2. Variables and equations of the BESF model

$$
\begin{gathered}
M=\sum_{j=1}^{n} M_{j}=\Delta X=\left|X_{m}-X_{1}\right| \\
\psi_{t}=k_{t} / k^{*} \\
X=\sum_{t=1}^{m} X_{t} \\
Z=\sum_{t=1}^{m} Z_{t}=\Delta V=\left|V_{n}-V_{1}\right| \\
V_{j}=\sum_{t=1}^{m} x_{t j}
\end{gathered}
$$




$$
\begin{gathered}
M_{j}=\left|x_{m j}-x_{1 j}\right| \\
k_{j}=x_{m j} / x_{1 j} \\
k=1+\left(M / X_{1}\right) \quad \text { (a) } \\
\ln k=M / X_{1} \\
k=X_{t-1} / X_{t} \\
\varepsilon=\frac{M}{Z}=\frac{\ln k \times X_{1}}{\ln \lambda \times V_{1}}=\frac{\Delta X}{\Delta V} \\
\psi=\sqrt[n]{\prod_{t=1}^{m} \psi_{t}}
\end{gathered}
$$

The parameter $K_{h}$ is an algebraically found macro-scale bound to emissions. Actually, it is the value taken on by the emission demand function $h_{t}$ when $X_{t}=X_{K}$. Hence, the first step to set $K_{h}$ is to find $X_{K}$, which is arrived at through vector algebra (Eq. (16)). Eq. (16) fulfils a twofold ideal requirement for sustainability:

a. Maximum economic efficiency $\left(k_{j}=k\right)$, so that the rates of economic growth or return even out across the sinks [3][24];

b. Perfect ecological efficiency $(\varepsilon=1)$, so that neither further reallocation nor redistribution of emissions removal takes place across the sinks [3][15][25].

Theoretically, these conditions not only allow the source-sink system to simultaneously reach its economic and ecological sustainability, but also require it to remain sustainably stable. Therefore, the stock level $X_{K}$ represents the "bio-economic cost" of achieving a stable state of sustainability. Rather than a target to be complied with, it translates into the space-time needed to make $k$ stable $\left(k_{j}=k\right)$ and $\varepsilon=1[3]$.

$$
2\left(\begin{array}{cc}
1 & \frac{\bar{k}^{-1}+\lambda^{-1}}{2} \\
\frac{\bar{k}+\lambda}{2} & 1
\end{array}\right)\left(\begin{array}{c}
-\bar{u}_{t} \\
\bar{v}_{t}
\end{array}\right)=\left(\begin{array}{l}
0 \\
0
\end{array}\right)
$$

In Eq. (16), the bar over the symbols stands for the corresponding mean values in the last row of Table 4. However, since the distribution of forestland $(\lambda)$ is known for every period and the release of emissions from deforestation $(k)$ instead is to be limited, $\bar{k}$ must be found by taking $\lambda=7.975, \bar{u}_{t}=24$ and $\bar{v}_{t}=182.40$ out of Table 4 . By so doing, it turns out that $\bar{k} \approx 7.23$ and $\bar{k}^{-1} \approx$ 0.1383. Next, by substituting these values into Eq. (17), in which, again, $\bar{u}_{t}=24$ and $\bar{X}_{t}=206.40$ come from Table $4, v_{K}=1319.20$ and $X_{K}=1492.78$ are finally found. 


\begin{tabular}{|c|c|c|c|c|c|c|c|}
\hline $\begin{array}{c}\text { Time } \\
\text { periods }(t)\end{array}$ & Years & $\begin{array}{c}\text { Deforest. } \\
\text { rates } \\
\left(10^{3} \mathrm{~km}^{2}\right)\end{array}$ & $\begin{array}{c}\text { Deforested } \\
\text { area } \\
\left(10^{3} \mathrm{~km}^{2}\right)^{\mathrm{a}}\end{array}$ & $\begin{array}{l}\text { Deforest. of the } \\
\text { original forest }^{b}\end{array}$ & $\begin{array}{c}\text { Forest } \\
\text { remnant } \\
\left(10^{3} \mathrm{~km}^{2}\right)^{\mathrm{c}}\end{array}$ & $\begin{array}{c}v_{t} \\
(G+C)^{d}\end{array}$ & $\begin{array}{c}u_{t} \\
(\mathrm{GtC})^{\mathrm{e}}\end{array}$ \\
\hline 1 & 1988 & 21.05 & 376.7 & $8.4 \%$ & 4107.3 & 190.58 & 16.35 \\
\hline 2 & 1989 & 17.77 & 401.4 & $9.0 \%$ & 4082.6 & 189.43 & 17.42 \\
\hline 3 & 1990 & 13.73 & 415.2 & $9.3 \%$ & 4068.8 & 188.79 & 18.02 \\
\hline 4 & 1991 & 11.03 & 426.4 & $9.5 \%$ & 4057.6 & 188.27 & 18.51 \\
\hline 5 & 1992 & 13.79 & 440.2 & $9.8 \%$ & 4043.8 & 187.63 & 19.10 \\
\hline 6 & 1993 & 14.90 & 440.2 & $9.8 \%$ & 4043.8 & 187.63 & 19.10 \\
\hline 7 & 1994 & 14.90 & 470.0 & $10.5 \%$ & 4014.0 & 186.25 & 20.40 \\
\hline 8 & 1995 & 29.06 & 497.1 & $11.1 \%$ & 3986.9 & 184.99 & 21.57 \\
\hline 9 & 1996 & 18.16 & 517.1 & $11.5 \%$ & 3966.9 & 184.06 & 22.44 \\
\hline 10 & 1997 & 13.23 & 530.1 & $11.8 \%$ & 3953.9 & 183.46 & 23.01 \\
\hline 11 & 1998 & 17.38 & 547.5 & $12.2 \%$ & 3936.5 & 182.65 & 23.76 \\
\hline 12 & 1999 & 17.26 & 564.7 & $12.6 \%$ & 3919.2 & 181.85 & 24.51 \\
\hline 13 & 2000 & 18.23 & 583.0 & $13.0 \%$ & 3901.0 & 181.01 & 25.30 \\
\hline 14 & 2001 & 18.17 & 601.1 & $13.4 \%$ & 3882.8 & 180.16 & 26.09 \\
\hline 15 & 2002 & 21.39 & 622.5 & $13.9 \%$ & 3861.4 & 179.17 & 27.02 \\
\hline 16 & 2003 & 25.25 & 647.8 & $14.4 \%$ & 3836.2 & 178.00 & 28.11 \\
\hline 17 & 2004 & 27.42 & 675.2 & $15.1 \%$ & 3808.8 & 176.73 & 29.30 \\
\hline 18 & 2005 & 18.85 & 694.0 & $15.5 \%$ & 3789.9 & 175.85 & 30.12 \\
\hline 19 & 2006 & 14.11 & 708.2 & $15.8 \%$ & 3775.8 & 175.20 & 30.73 \\
\hline 20 & 2007 & 11.53 & 719.7 & $16.1 \%$ & 3764.3 & 174.66 & 31.23 \\
\hline 21 & 2008 & 12.91 & 732.6 & $16.3 \%$ & 3751.4 & 174.06 & 31.79 \\
\hline 22 & 2009 & 7.46 & 740.1 & $16.5 \%$ & 3743.9 & 173.72 & 32.12 \\
\hline 23 & 2010 & 7.00 & 747.1 & $16.7 \%$ & 3736.9 & 173.39 & 32.42 \\
\hline 24 & 2011 & 6.42 & 753.5 & $16.8 \%$ & 3730.5 & 173.09 & 32.70 \\
\hline 25 & 2012 & 4.57 & 758.0 & $16.9 \%$ & 3725.9 & 172.88 & 32.90 \\
\hline
\end{tabular}

(a) According to [21], until 1997, and thereafter calculated from the previous deforested area plus the yearly deforestation rate. (b) Figures in this column are obtained by dividing the deforested area by estimates that consider $4483.972 \times 10^{3}$ $\mathrm{km}^{2}=4.483972 \times 10^{6} \mathrm{~km}^{2}$ as, approximately, the original forested area of Brazil's $5 \times 10^{6} \mathrm{~km}^{2}$ Legal Amazon [22]. (c) Figures obtained by calculating $4483.972 \times 10^{3} \mathrm{~km}^{2}$ - deforested area $\times 10^{3} \mathrm{~km}^{2}$. (d) "For the region's forests as a whole, the mean biomass loading (t/ha) for pre-logging biomass (weighted by the area of each eco-region present) is estimated at $464 \mathrm{t} / \mathrm{ha"}$ " [22]. So the figures in this column result from $464 \mathrm{t} / \mathrm{ha} \times$ forest remnant $\times 10^{3} \mathrm{~km}^{2}=464 \mathrm{t} / 10^{-2} \mathrm{~km}^{2} \times$ forest remnant $\times 10^{3} \mathrm{~km}^{2}=\left(464 \times\right.$ forest remnant $\left.\times 10^{5}\right) \mathrm{t}=\left(464 \times\right.$ forest remnant $\left.\times 10^{5}\right) 10^{-9} \mathrm{Gt}$. (e) The loading (biomass per hectare) for pre-logging biomass of forests cleared in 1990 (weighted by the deforestation rate in each state) is calculated at $434 \mathrm{t} / \mathrm{ha}$. As before, the figures in this column result from $434 \mathrm{t} / \mathrm{ha} \times$ forest remnant $\times 10^{3} \mathrm{~km}^{2}=434 \mathrm{t} / 10^{-2} \mathrm{~km}^{2} \times$ forest remnant $\times 10^{3} \mathrm{~km}^{2}=\left(434 \times\right.$ forest remnant $\left.\times 10^{5}\right) \mathrm{t}=\left(434 \times\right.$ forest remnant $\left.\times 10^{5}\right) 10^{-9} \mathrm{Gt}[22]$.

Source: [23]

Table 3. Forest conservation and deforestation in the Brazilian Legal Amazon (1988-2012) 


$$
\left(\begin{array}{cc}
1 & \bar{k}^{-1} \\
\bar{k} & 1
\end{array}\right)\left(\begin{array}{l}
\bar{u}_{t} \\
v_{K}
\end{array}\right)=\left(\begin{array}{l}
\bar{X}_{t} \\
X_{K}
\end{array}\right)
$$

\section{Removal demand function $\left(\hat{h}_{t}\right)$}

In an emissions-saving (low carbon) economy, a seesaw balance between deforestation and conservation of carbon stocks is expected to hold. At lower deforestation rates, the savings (conservation) of biomass stocks outstrip their consumption. But as economic growth increases, conservation savings of biomass stocks decline, while their consumption by deforestation goes up. Thus, in order to account for these offsetting effects at any time, the observed removal demands for deforestation and conservation are respectively determined by:

$$
\begin{aligned}
& h_{t}\left(u_{t}\right)=\bar{u}_{t}-u_{t} \\
& h_{t}\left(v_{t}\right)=\bar{v}_{t}-v_{t}
\end{aligned}
$$

where $\bar{u}_{t}$ and $\bar{v}_{t}$ are mean values for either biomass stock, displayed in the last row of Table 4 .

By summing Eqs. (18) and (19), the total observed demand for removal per period is obtained:

$$
h_{t}=\bar{x}_{t}-x_{t}
$$

where $\mathrm{x}_{\mathrm{t}}=\mathrm{u}_{\mathrm{t}}+\mathrm{v}_{\mathrm{t}}$ and $\bar{x}_{t}=\bar{u}_{t}+\bar{v}_{t}$.

The underlying assumption of Eqs. (18)-(20) is the Permanent Income Hypothesis (PIH), put forward by the American economist Milton Friedman in the late 1950. According to this hypothesis, consumption is smoothed in the long run, so as to handle short-run fluctuations in income. Income fluctuates because of its transitory component, which consists of unforeseen additions or subtractions likely to cancel out in the long run [26][27]. In an emissions avoiding world, where carbon storage sounds like the economy's earnings, conservation of carbon stocks adds to income, whereas deforestation lessens it. So, Eq. (20) amounts to the permanent component of income in the long run, which accounts for a smoother path based on consumption expectations $\left(\bar{x}_{t}\right)$ rather than on current consumption $\left(x_{t}\right)$. The regression ${ }^{5}$ of the results for Eq. (20) on the observed values for $X_{t}$, in Table 5, yields the estimated long-run mean of removal demand (Eq. (21)).

$$
\begin{array}{cc}
\quad \hat{h}_{t}=206.121-0.999 X_{t} \\
\text { t- stat. } 497.034 & -496.808 \\
\text { sig.t. } 0.0000 & 0.0000
\end{array}
$$




\begin{tabular}{|c|c|c|c|c|c|c|c|c|c|c|c|c|}
\hline $\begin{array}{c}\text { Time } \\
\text { periods }\end{array}$ & $\frac{n}{\stackrel{n}{\varpi}}$ & 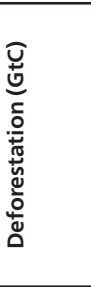 & 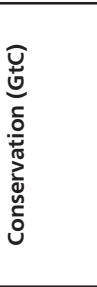 & 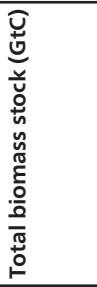 & 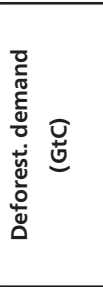 & 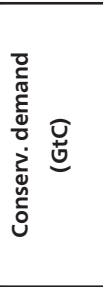 & 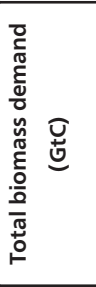 & 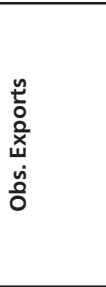 & 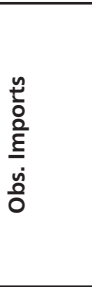 & $\omega$ & 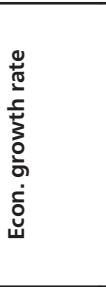 & 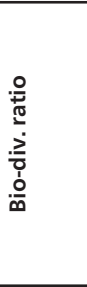 \\
\hline$(t)$ & & $\left(u_{t}\right)$ & $\left(v_{t}\right)$ & $\left(X_{t}\right)$ & Eq. (18) & Eq. (19) & Eq. (20) & $\begin{array}{c}\left(Z_{t}\right) \\
\text { Eq. }(2)\end{array}$ & $\begin{array}{c}(M) \\
\text { Eq. (6) }\end{array}$ & $\begin{array}{l}\text { Eq. } \\
(14)\end{array}$ & $\begin{array}{c}(k) \\
\text { Eq. }(13 c)\end{array}$ & $\begin{array}{c}\left(\lambda_{t}\right) \\
\text { Eq. (3) }\end{array}$ \\
\hline 1 & 1988 & 16.35 & 190.58 & 206.93 & 7.65 & -8.18 & -0.53 & 174.23 & - & - & 1.00036 & 11.657 \\
\hline 2 & 1989 & 17.42 & 189.43 & 206.85 & 6.57 & -7.03 & -0.45 & 172.01 & 2.2181 & 12.9 & 1.00020 & 10.874 \\
\hline 3 & 1990 & 18.02 & 188.79 & 206.81 & 5.98 & -6.39 & -0.41 & 170.77 & 1.2392 & 7.3 & 1.00016 & 10.477 \\
\hline 4 & 1991 & 18.51 & 188.27 & 206.78 & 5.49 & -5.87 & -0.38 & 169.77 & 1.0058 & 5.9 & 1.00020 & 10.174 \\
\hline 5 & 1992 & 19.10 & 187.63 & 206.74 & 4.89 & -5.23 & -0.34 & 168.53 & 1.2392 & 7.4 & 1.00000 & 9.821 \\
\hline 6 & 1993 & 19.10 & 187.63 & 206.74 & 4.89 & -5.23 & -0.34 & 168.53 & 0.0000 & 0.0 & 1.00043 & 9.821 \\
\hline 7 & 1994 & 20.40 & 186.25 & 206.65 & 3.60 & -3.85 & -0.25 & 165.85 & 2.6760 & 16.1 & 1.00039 & 9.131 \\
\hline 8 & 1995 & 21.57 & 184.99 & 206.57 & 2.42 & -2.59 & -0.17 & 163.42 & 2.4336 & 14.9 & 1.00029 & 8.575 \\
\hline 9 & 1996 & 22.44 & 184.06 & 206.51 & 1.55 & -1.66 & -0.11 & 161.62 & 1.7960 & 11.1 & 1.00019 & 8.202 \\
\hline 10 & 1997 & 23.01 & 183.46 & 206.47 & 0.99 & -1.06 & -0.07 & 160.45 & 1.1674 & 7.3 & 1.00025 & 7.974 \\
\hline 11 & 1998 & 23.76 & 182.65 & 206.41 & 0.23 & -0.25 & -0.02 & 158.89 & 1.5610 & 9.8 & 1.00025 & 7.687 \\
\hline 12 & 1999 & 24.51 & 181.85 & 206.36 & -0.51 & 0.55 & 0.04 & 157.34 & 1.5499 & 9.9 & 1.00027 & 7.420 \\
\hline 13 & 2000 & 25.30 & 181.01 & 206.31 & -1.31 & 1.40 & 0.09 & 155.71 & 1.6367 & 10.5 & 1.00026 & 7.154 \\
\hline 14 & 2001 & 26.09 & 180.16 & 206.25 & -2.09 & 2.24 & 0.14 & 154.07 & 1.6312 & 10.6 & 1.00031 & 6.906 \\
\hline 15 & 2002 & 27.02 & 179.17 & 206.19 & -3.02 & 3.23 & 0.21 & 152.15 & 1.9212 & 12.6 & 1.00037 & 6.632 \\
\hline 16 & 2003 & 28.11 & 178.00 & 206.11 & -4.12 & 4.40 & 0.28 & 149.89 & 2.2672 & 15.1 & 1.00040 & 6.331 \\
\hline 17 & 2004 & 29.30 & 176.73 & 206.03 & -5.31 & 5.68 & 0.37 & 147.42 & 2.4626 & 16.7 & 1.00027 & 6.031 \\
\hline 18 & 2005 & 30.12 & 175.85 & 205.97 & -6.13 & 6.55 & 0.42 & 145.73 & 1.6924 & 11.6 & 1.00021 & 5.838 \\
\hline 19 & 2006 & 30.73 & 175.20 & 205.93 & -6.74 & 7.20 & 0.47 & 144.46 & 1.2670 & 8.8 & 1.00017 & 5.700 \\
\hline 20 & 2007 & 31.23 & 174.66 & 205.90 & -7.24 & 7.74 & 0.50 & 143.43 & 1.0356 & 7.2 & 1.00019 & 5.592 \\
\hline 21 & 2008 & 31.79 & 174.06 & 205.86 & -7.80 & 8.34 & 0.54 & 142.27 & 1.1594 & 8.1 & 1.00011 & 5.475 \\
\hline 22 & 2009 & 32.12 & 173.72 & 205.84 & -8.12 & 8.68 & 0.56 & 141.60 & 0.6703 & 4.7 & 1.00010 & 5.409 \\
\hline 23 & 2010 & 32.42 & 173.39 & 205.82 & -8.43 & 9.01 & 0.58 & 140.97 & 0.6286 & 4.5 & 1.00009 & 5.348 \\
\hline 24 & 2011 & 32.70 & 173.09 & 205.80 & -8.71 & 9.31 & 0.60 & 140.39 & 0.5763 & 4.1 & 1.00007 & 5.293 \\
\hline 25 & 2012 & 32.90 & 172.88 & 205.78 & -8.90 & 9.52 & 0.62 & 139.98 & 0.4105 & 2.9 & - & 5.255 \\
\hline Mean & & 24.00 & 182.40 & 206.40 & & & & & & & 1.00023 & 7.975 \\
\hline
\end{tabular}

Table 4. Observed deforested, conserved and demanded biomass in the Brazilian Legal Amazon (1988-2012) 


\begin{tabular}{|c|c|c|c|c|c|c|c|c|}
\hline $\begin{array}{c}\text { Time } \\
\text { periods }\end{array}$ & Years & $\begin{array}{c}X_{t} \\
(\mathrm{GtC})\end{array}$ & $\begin{array}{c}h_{t} \\
(\mathrm{GtC})\end{array}$ & $\begin{array}{c}\hat{h}_{t} \\
(\mathrm{GtC})\end{array}$ & $\begin{array}{c}g\left(v\left(X_{t}\right)\right) \\
(\mathrm{GtC})\end{array}$ & $\begin{array}{l}\hat{F}\left(X_{t}\right) \\
(\mathrm{GtC})\end{array}$ & $\begin{array}{l}G\left(X_{t}\right) \\
(\mathrm{GtC})\end{array}$ & $\begin{array}{l}\hat{G}\left(X_{t}\right) \\
(\mathrm{GtC})\end{array}$ \\
\hline$(t)$ & & & Eq.(20) & Eq.(21) & Eq.(23) & Eq.(25) & Eq.(26) & Eq.(27) \\
\hline$T$ & $?$ & 1492.78 & - & -1285.17 & 0.0000 & 0.00 & -1492.78 & $1.25 \times 10^{7}$ \\
\hline 1 & 1988 & 206.93 & -0.53 & -0.5983 & 0.5370 & 1431.25 & 1224.33 & 1215.00 \\
\hline 2 & 1989 & 206.85 & -0.45 & -0.5242 & 0.5376 & 1252.76 & 1045.91 & 1039.41 \\
\hline 3 & 1990 & 206.81 & -0.41 & -0.4829 & 0.5379 & 1153.21 & 946.40 & 941.33 \\
\hline 4 & 1991 & 206.78 & -0.38 & -0.4493 & 0.5382 & 1072.51 & 865.73 & 861.74 \\
\hline 5 & 1992 & 206.74 & -0.34 & -0.4080 & 0.5386 & 973.18 & 766.45 & 763.70 \\
\hline 6 & 1993 & 206.74 & -0.34 & -0.4080 & 0.5386 & 973.18 & 766.45 & 763.70 \\
\hline 7 & 1994 & 206.65 & -0.25 & -0.3187 & 0.5393 & 759.12 & 552.47 & 552.05 \\
\hline 8 & 1995 & 206.57 & -0.17 & -0.2374 & 0.5400 & 564.94 & 358.38 & 359.66 \\
\hline 9 & 1996 & 206.51 & -0.11 & -0.1775 & 0.5405 & 421.94 & 215.44 & 217.72 \\
\hline 10 & 1997 & 206.47 & -0.07 & -0.1385 & 0.5409 & 329.13 & 122.67 & 125.48 \\
\hline 11 & 1998 & 206.4139 & -0.02 & -0.0864 & 0.5413 & 205.20 & -1.22 & 2.17 \\
\hline 12 & 1999 & 206.36 & 0.04 & -0.0347 & 0.5418 & 82.34 & -124.02 & -120.23 \\
\hline 13 & 2000 & 206.31 & 0.09 & 0.0199 & 0.5422 & -47.19 & -253.50 & -249.45 \\
\hline 14 & 2001 & 206.25 & 0.14 & 0.0744 & 0.5427 & -176.08 & -382.33 & -378.21 \\
\hline 15 & 2002 & 206.19 & 0.21 & 0.1385 & 0.5433 & -327.61 & -533.80 & -529.81 \\
\hline 16 & 2003 & 206.11 & 0.28 & 0.2141 & 0.5439 & -506.05 & -712.16 & -708.66 \\
\hline 17 & 2004 & 206.03 & 0.37 & 0.2963 & 0.5446 & -699.41 & -905.44 & -902.84 \\
\hline 18 & 2005 & 205.97 & 0.42 & 0.3528 & 0.5451 & -832.02 & -1037.99 & -1036.24 \\
\hline 19 & 2006 & 205.93 & 0.47 & 0.3951 & 0.5455 & -931.14 & -1137.07 & -1136.09 \\
\hline 20 & 2007 & 205.90 & 0.50 & 0.4296 & 0.5458 & -1012.07 & -1217.97 & -1217.69 \\
\hline 21 & 2008 & 205.86 & 0.54 & 0.4683 & 0.5461 & -1102.58 & -1308.43 & -1309.03 \\
\hline 22 & 2009 & 205.84 & 0.56 & 0.4907 & 0.5463 & -1154.85 & -1360.68 & -1361.82 \\
\hline 23 & 2010 & 205.82 & 0.58 & 0.5117 & 0.5465 & -1203.84 & -1409.66 & -1411.33 \\
\hline 24 & 2011 & 205.80 & 0.60 & 0.5309 & 0.5466 & -1248.73 & -1454.53 & -1456.72 \\
\hline 25 & 2012 & 205.78 & 0.62 & 0.5446 & 0.5468 & -1280.69 & -1486.47 & -1489.04 \\
\hline
\end{tabular}

Table 5. Observed forest data and estimated demand $\left(\hat{h}_{t}\right)$ and supply $\left(\hat{G}\left(X_{t}\right)\right)$ functions of the BESF model

\section{Removal supply function $\left(\hat{G}\left(X_{t}\right)\right)$}

By substituting, in Eq. (21), $X_{K}=1492.78$, found by Eqs. (16) and (17), for $X_{t}$, the least level of emissions demand $K_{h}=-1286.16$ comes out. This value is used as the lower limit of a logistic function (Eq. (23)) in the following constrained optimisation problem: 
Objective function:

$$
\min _{X_{t}} \sum_{t} S_{t}=\min _{X_{t}} \sum_{t}\left[g\left(v\left(X_{t}\right)\right)-\hat{h}_{t}\right]
$$

\section{Constraints:}

Constraint I:

$$
\hat{h}_{t}=206.121-0.999 X_{t}
$$

Constraint II:

$$
\begin{gathered}
g\left(v\left(X_{t}\right)\right)=\frac{1}{\left(1 / K_{h}\right)+b_{0} b_{1}{ }^{{ }_{t}}} \\
g\left(v\left(X_{t}\right)\right)=\frac{1}{(1 /-1286.16)+0.07075414 \times 1.01593216^{X_{t}}}
\end{gathered}
$$

Constraint III:

$$
g\left(v\left(X_{t}\right)\right) \geq \hat{h}_{t}
$$

where $S_{t}$ stands for the instantaneous surplus arising from the gap between removal growth rates $\left(g\left(v\left(X_{t}\right)\right)\right)$ and removal consumption rates $\left(h_{t}\right)$. Because of Eq. (24), $S_{t} \geq 0$, that is, at any time, the rate at which removal stocks are supplied must be greater than or equal to the rate at which they are demanded. In Eq. (23), the parameter $K_{h}$ is found by Eqs. (16), (17) and (21), whereas the parameters $b_{0}$ and $b_{1}$ are provided by GAMS-IDE (General Algebraic Modelling System - Integrated Development Environment), version 24.1.2 (http://www.gams.com/ download/), in which the optimisation programme described by Eqs. (21)-(24) was run.

The optimal values for $g\left(v\left(X_{t}\right)\right)$ are displayed in Table 5. They are now employed to estimate the future supply of removal stocks $\left(F\left(X_{t}\right)\right)$ given the existing ones $\left(X_{t}\right)$, used up in the present. The estimated variable $\hat{F}\left(X_{t}\right)$ stands for an outflow-inflow ratio, defined by logistically constrained rates of demand (numerator) and supply (denominator) of removal stocks (Eq. (25)). The difference between $F\left(X_{t}\right)$ and $X_{t}$ is the removal supply per time period $\left(G\left(X_{t}\right)\right)$. Starting from the values for $G\left(X_{t}\right)$, found by Eq. (26) and displayed in Table 5, it is possible to estimate the removal supply function (Eq. (27)), whose values are also displayed in Table 5.

$$
\begin{gathered}
\hat{F}\left(X_{t}\right)=\frac{\partial \hat{h}_{t} / \partial X_{t}}{g\left(v\left(X_{t}\right)\right)}=\frac{\hat{h}_{t}\left(K_{h}-\hat{h}_{t}\right)}{g\left(v\left(X_{t}\right)\right)} \\
G\left(X_{t}\right)=\hat{F}\left(X_{t}\right)-X_{t}
\end{gathered}
$$




$$
\begin{array}{lrc}
\hat{G}\left(X_{t}\right)= & 5.727 X_{t}^{2} & -244006.276 \\
\text { t-stat. } & 588.143 & -588.763 \\
\text { sig.t. } & 0.0000 & 0.0000
\end{array}
$$

\section{Avoiding deforestation versus stock maintenance approach}

All removal market functions are drawn in Figure 3. They look like those in Figure 2.c, and their interplay shows how long emissions from deforestation can be removed by natural forest stocks. In deforestation-conservation settings, the cost of maintaining a high economic growth rate $(\ln k)$ would be an abrupt fall in the rate at which natural removal stocks grow $(\ln \lambda)$. As demonstrated by Eq. (3), in Table 2, and by the figures in the last column of Table 4, the value of $\lambda$ indirectly defines the quantities of removal consumption $\left(h_{t}\right)$ from deforestation $\left(u_{t}\right)$ or removal savings from conservation $\left(v_{t}\right)$. Thus, $h_{t}$ (Eq. (21)) hinges on that sink distribution, and so does $\hat{G}\left(X_{t}\right)$ (Eq. (27)), whose estimation ultimately relies on $K_{h}-$ the lower bound of removal demand. As a matter of fact, $\lambda$ is the critical variable drawing the bottom line in carbon removal markets.

The impacts of $\lambda$ on the equilibrium of removal markets are shown in Table 6 . The equilibrium scenarios checked, but the BESF one, follow the standard fishery analysis [28]. In the context of deforestation and forest conservation, though, there are important remarks regarding equilibrium conditions. To begin with, although the MSY equilibrium might apply to unnatural, even-aged stands, it is not likely to suit the dynamics of conservation of natural forests and deforestation. It is known that in natural forests, the wide frequency and age range of tree species points to a biomass yielding function that does not reach a maximum sustainable yield. Mathematically, this is translated by taking the first derivative of Eq. (27) and making it equal to zero. Thus, it is found that $X_{\mathrm{MSY}}=21303.15 \mathrm{GtC}$, which is a prohibitively high level of removal stocks, provided their logistic upper bound is $X_{K}=1492.78$. The same holds for the restricted access (RA) stock level, which is found to be slightly lower $\left(X_{\mathrm{RA}}=21303.06 \mathrm{GtC}\right)$.

Although in standard bio-economic (fishery) analysis, the latter is expected to be higher than the former, it must be borne in mind that, in a compensation approach - such as avoiding deforestation -, the demand for removal stocks grows with deforestation (Figure 4.a). Therefore, conservation requires $X_{\mathrm{MSY}}>X_{\mathrm{RA}}$, since a smaller compensating stock means that less deforestation occurred.

On the other hand, Figure 3 shows that the greater the stock, the smaller its demand is, because the stock can only grow when its depletion is low. Thus, as is clear so far, Figure 3 illustrates a rather different standpoint, namely, a stock maintenance approach (Figure 4.b). It has been argued that such a conservation approach favours the largest forest countries, like Brazil. Unlike in small forest countries, with only tiny remnants of forest left, in countries where large expanses of forest remain standing, stock maintenance represents a much greater carbon service than does avoiding deforestation [21]. 
In this regard, the equilibrium conditions in Table 6 had to be adjusted to fall within a stock maintenance rationale. Since, in Figure 3, the slopes of the functions $G\left(X_{t}\right)$ (Eq. (27)) and $h_{t}$ (Eq. (21)) are never expected to be equal - as the columns labelled "rate of return" and "rate of depletion" in Table 6 also show - within the feasible region $\left(X_{0 \mathrm{~A}} \leq X_{t}^{*} \leq X_{K}\right)$, RA equilibrium only calls for maximising some positive level of $Y_{t}$, which could otherwise be warranted if the functions $G\left(X_{t}\right)$ and $h_{t}$ were to have the same slopes somewhere. However, as the outcomes in Table 6 show, a positive $Y_{t}$ can be accomplished with a negative value for $\hat{G}\left(X_{t}\right)$, provided that, in absolute terms, this is smaller than that for $\hat{h}_{t}$. Since $\hat{G}\left(X_{t}\right)<0$ is environmentally threatening, BESF equilibrium becomes a more stringent condition, because it calls both for positive $Y_{t}$ and $G\left(X_{t}\right)$. By minimising this positive level of $Y_{t}$, then, the BESF equilibrium ensures that, for a removal demand function like $h_{t}$, in Figure $4 . \mathrm{b}$, and $\hat{h}_{t}$, in Figure 3 , the stock level satisfying this will lie slightly beyond (greater than) $K-$ the stock level at which $\hat{G}\left(X_{t}\right)$ $=0-$ and further beyond (greater than) $X_{\mathrm{OA}}-$ where $\hat{G}\left(X_{t}\right)$ becomes equal to $\hat{h}_{t}$, but turns out to be negative.

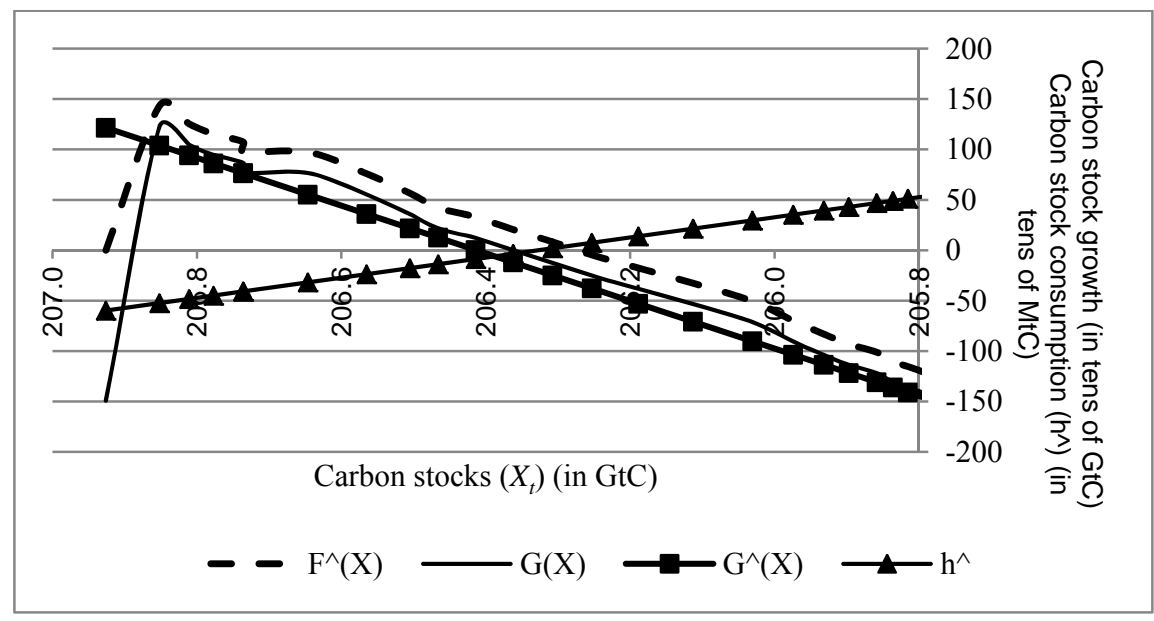

Figure 3. Removal market functions

The open access stock level $\left(X_{\mathrm{OA}}\right)$ is the smallest, yet just slightly smaller than the others. As expected from standard theory on renewable resources, the economic rent at this level is zero. At any other equilibrium point, it is non-zero and positive. But it is the highest at BESF, which minimises the throughput of maintaining stocks by requiring the supply of their emissions removal services $\left(G\left(X_{t}\right)\right)$ always to be positive.

Finally, by comparing the optimal stock levels $\left(X_{t}^{*}\right)$, in Table 6, with the observed ones $\left(X_{t}\right)$, in Table 5, it can be inferred when each equilibrium scenario must have occurred. It is worrying to ascertain that all of them are already gone somewhere between 1998 and 1999. 


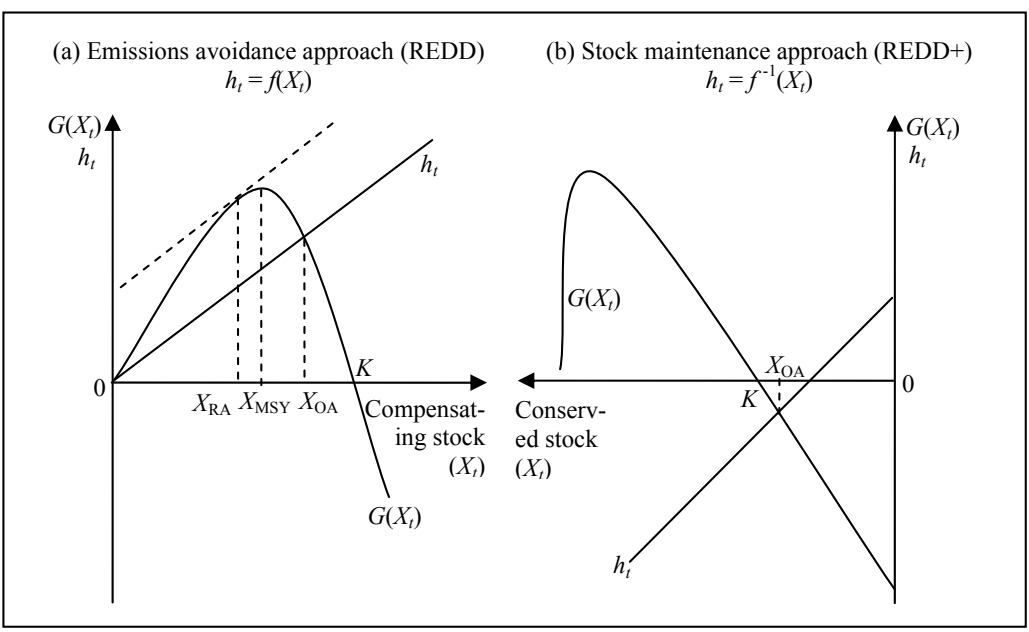

Figure 4. The BESF model functions and the REDD approaches

\begin{tabular}{|c|c|c|c|c|c|c|c|}
\hline \multirow{3}{*}{ Equilibriaa } & \multirow{3}{*}{$\begin{array}{l}\text { Equilibrium } \\
\text { conditions }^{b}\end{array}$} & \multirow{2}{*}{$\begin{array}{l}\text { Optimal' stock } \\
\qquad\left(\mathrm{X}_{\mathrm{t}}{ }^{*}\right)\end{array}$} & $\begin{array}{l}\text { Removal supply } \\
\qquad\left(\hat{G}\left(X_{t}^{*}\right)\right)\end{array}$ & $\begin{array}{c}\text { Removal } \\
\text { demand }\left(h_{t}^{*}\right)\end{array}$ & \multirow{3}{*}{$\begin{array}{l}\text { Rate of } \\
\text { returnd } \\
\left(\frac{d \hat{G}\left(x_{t}^{*}\right)}{d x_{t}^{*}}\right)\end{array}$} & \multirow{3}{*}{$\begin{array}{l}\text { Rate of } \\
\text { depletione } \\
\left(\frac{d \hat{h}_{t}^{*}}{d x_{t}^{*}}\right)\end{array}$} & \multirow{3}{*}{$\begin{array}{l}\text { Economic rent } \\
\qquad\left(Y_{t}=\right. \\
\left.\hat{G}\left(X_{t}^{*}\right)-\hat{h}_{t}^{*}\right)\end{array}$} \\
\hline & & & Eq. (27) & Eq. (21) & & & \\
\hline & & (in GtC) & (in GtC) & (in GtC) & & & \\
\hline \multirow[t]{2}{*}{ BESF } & $\begin{array}{l}\min Y_{t}>0 \\
\hat{G}\left(X_{t}\right)>0\end{array}$ & 206.412933 & $\rightarrow 0.000$ & -0.086 & 2.364 & 0.999 & $>0.086$ \\
\hline & $X_{\mathrm{OA}} \leq X_{t}^{*} \leq X_{K}$ & & & & & & \\
\hline K & $\hat{G}\left(X_{t}\right)=0$ & 206.412933 & 0.000 & -0.086 & 2.364 & 0.999 & 0.086 \\
\hline MSY & $\begin{array}{c}\frac{d \hat{G}\left(X_{t}\right)}{d X_{t}}=0 \\
X_{\mathrm{OA}} \leq X_{t}^{*} \leq X_{K}\end{array}$ & - & - & - & - & - & - \\
\hline RA & $\begin{array}{c}\max Y_{t}>0 \\
X_{\mathrm{OA}} \leq X_{t}^{*} \leq X_{K}\end{array}$ & 206.412933 & $-3.49 \times 10^{-10}$ & -0.086 & 2.364 & 0.999 & $<0.086$ \\
\hline OA & $\hat{G}\left(x_{t}\right)=\hat{h}_{t}$ & 206.412898 & -0.08 & -0.08 & 2.364 & 0.999 & 0.000 \\
\hline
\end{tabular}

(a) BESF = Bio-Economic carbon Sequestration by Forests; $\mathrm{K}=$ steady-state equilibrium; MSY = Maximum Sustainable Yield; RA = Restricted Access equilibrium; OA = Open Access equilibrium. (b) In standard fishery models, however, $X_{R A}$ is found where $d \hat{G}\left(X_{t}\right) / d X_{t}=d \hat{h}_{t} / d X_{t}$. (c) Provided by GAMS-IDE 24.1.2. (d) First derivative of Eq. $(27)=11.454 X_{t}$. However, so that $\hat{G}\left(X_{t}\right)$ and $\hat{h}_{t}$ can be plotted together, the barter ratio between them is $10 \mathrm{GtC}$ of $\hat{G}\left(X_{t}\right)$ per $10 \mathrm{MtC}$ of $\hat{h}_{t}$, as the vertical axis of the graph in Figure 3 indicates. More simply, this barter ratio can be expressed as $1 \mathrm{GtC}: 1$ $\mathrm{MtC}$, which means $10^{3} \mathrm{MtC}: 1 \mathrm{MtC}$. Therefore, so that rates of return and depletion can be compared with one another, the former must be multiplied by $10^{-3}$. (e) First derivative of Eq. (21).

Table 6. Removal market equilibrium analysis 


\section{Aggregate emissions demand or removal supply function $(\grave{\lambda}(\hat{\varepsilon}))$}

Perhaps these worries could have been dismissed before, if the variable regulating land-use changes $(\lambda)$ had not been overlooked. As seen, $\varepsilon$ (Eq. (14)) - the bio-economic exchange rate - is defined as the ratio of ecological debt - excess demand for removal services (supply of emissions) - to ecological credit - excess supply of removal services (demand for emissions). Although it is an underlying variable, it stands for the shadow price measuring, along an optimal path through time, the marginal bio-economic value of the forestland asset [19]. When the speed $k$ of economic activity drives deforestation, forestland shrinks and thus $\varepsilon$ is expected to rise (depreciate).

Since $\varepsilon$ critically and ultimately depends on $\lambda$ and $k$, it must, to begin with, be expressed in terms of them. Methodologically, this can be first accomplished by fixing $k=\bar{k}=1.00023$, given in the last row of Table 4 . Then this rate is assumed to hold for every year according to the following rule:

$$
X_{t-1} / X_{t}^{\prime}=\bar{k}=1.00023
$$

where $X_{t}^{\prime}$ is the stock level that would be observed in column $X_{t}$ of Table 5, if $k=\bar{k}=1.0023$.

As $\lambda$ changes, so will $\varepsilon-$ whose calculation follows Eqs. (11) and (6), for $M$ (imports); (2) and (9), for $Z$ (exports); and (14), for $\varepsilon$ proper. These outcomes must be ordered pair-wise, according to increasing values of $\lambda$. The objective of this disposition is to check how $\varepsilon$ is affected by changes in $\lambda$. Next, an equation for $\varepsilon$, as a long-run function (thus, bearing no $t$ index) of $\lambda$, is estimated:

$$
\begin{array}{lrl}
\hat{\varepsilon}(\lambda)=\exp \left(-0.131+\frac{1.096}{\ln \ln \lambda}\right) \\
\text { t- stat. } \quad-243.522 & 1048.581 \\
\text { sig.t. } & 0.0000 & 0.0000
\end{array}
$$

Finally, the results for $\hat{\varepsilon}(\lambda)$, in Eq. (29), are used as inputs (independent variables) to arrive at an equation for $\lambda$ as a long-run function of $\varepsilon$ :

$$
\begin{array}{lrr}
\ln \hat{\lambda}(\hat{\varepsilon})=\exp \left(-1.127+\frac{2.766}{\hat{\varepsilon}}\right) \\
\text { t- stat. } \quad-133.522 & 214.563 \\
\text { sig.t. } & 0.0000 & 0.0000
\end{array}
$$

Eq. (30) stands for the aggregate emissions demand or removal supply function in the long run. 


\section{Aggregate emissions supply or removal demand function $\left(k\left(\begin{array}{l}\prime \\ \varepsilon\end{array}\right)\right)$}

By a similar procedure, the functional relationship between $\varepsilon$ and $k$, as well as between $k$ and $\varepsilon$, can then be calculated. This time, though, the variable made fixed is $\lambda=\lambda=7.975$, given in the last row of Table 4 . This value is kept unchanged for each two consecutive years, to either of which Eqs. (1) and (3) apply:

$$
\begin{gathered}
x_{t, j}+x_{t, j+1}=X_{t} \\
x_{t, j+1} / x_{t, j}=\lambda=7.975
\end{gathered}
$$

By substituting Eq. (3)a into Eq. (1)a, it turns out that:

$$
X_{t}=(1+\pi) x_{t, j}
$$

which can be correspondingly replaced in Eq. (13)c to find the new value of $k$, at each two consecutive periods, when $\lambda=\lambda=7.975$ and thence remains constant. Again, the resulting $\varepsilon$ requires Eqs. (11), (6), (2), (9) and (14). Also, like before, so as to inquire into the effects of changing $k$ on $\varepsilon$, these variables are taken pair-wise on an increasing order of $k$ values. Lastly, an equation for $\varepsilon$, as a long-run function (thus, bearing no $t$ index) of $k$, can be estimated:

$$
\begin{aligned}
& \hat{\varepsilon}(k)=6434.098 \ln \ln k \\
& \text { t- stat. } 3921.720 \\
& \text { sig.t. } 0.0000
\end{aligned}
$$

Now, the outcomes for $\hat{\varepsilon}(k)$, in Eq. (31), are used as inputs (independent variables) to obtain an equation for $k$ as a long-run function of $\varepsilon$ :

$$
\begin{aligned}
& \hat{k}(\hat{\varepsilon})=0.99999998+1.554575 \times 10^{-4} \hat{\varepsilon} \\
& \text { t-stat. - - } \\
& \text { sig.t. - - }
\end{aligned}
$$

Eq. (32) stands for the aggregate emissions supply or removal demand function in the long run.

\section{Macro-bio-economic scenarios}

Based on Eqs. (30) and (32), REDD, CDM and BAU scenarios are tested to understand how well conservation (REDD) and compensation (CDM) strategies can do as compared with 
business-as-usual (BAU) ones (Table 7 and Table 8). The most useful results shown by Table 8 are those displayed in its last two columns. They make clear how much the natural forest and the economy are expected to grow annually, through 25 years, in each scenario.

It is noteworthy that a stringent conservation scenario, such as REDD1, requires an optimal value for $\lambda\left(\hat{\lambda}_{\text {REDD1 }}^{*}=5.787\right)$ that is not too far from its observed mean value, displayed in the last row and column of Table $4(\lambda=7.975)$. Thus, the allowed annual deforestation rate through 25 years (Eq. (33)) is $3.18 \%$ p.a. (last column of Table 8 ). This figure might sound startling when compared, for instance, with the deforestation rate in the Brazilian Legal Amazon for a single year: just between August 2012 and August 2013, this rate reached 20\% [31]! However, neither would more "economic growth-driven" strategies (CDM and BAU's) stand such a high annual deforestation rate. Nearly all of them (last four rows and last column of Table 8 ) would allow for a yearly deforestation rate of about $7.8 \%$. On the other hand, a 100\% rate of deforestation reduction, even spread over 25 years (scenario REDD2), would render no more than an economic growth rate as low as $0.00149 \%$ (last column of Table 8 ). These numbers help shed some light on the feasibility of the targets set by deforestation reduction programmes [29] (Figure 7). Figure 5 shows that the supply of emissions $(k)$ is nearly perfectly inelastic to the shadow price $\varepsilon$, whereas the removal of them $(\hat{\lambda})$ dramatically falls with the rise of $\varepsilon$. Although at some high value of $\varepsilon$, the demand for removal also becomes almost inelastic to price changes, this only happens at very low levels of existing removal stocks, when thus $\hat{\lambda} \rightarrow 1$ (Eq. (3)) and the share of forest conservation approaches that of deforestation $(v \rightarrow u)$ or becomes even smaller $(\mathrm{v}<\mathrm{u})$.

\begin{tabular}{|c|c|c|}
\hline Scenario & Constraints & Objective-function $\left(W \text { or } W^{\prime}\right)^{a}$ \\
\hline REDD1 & $\widehat{\ln \lambda}>\ln \hat{k} ; \widehat{\ln \lambda}=1.755682^{\mathrm{b}}$ & $\max W=\widehat{\ln \lambda}-\hat{k}$ \\
\hline REDD2 & $\widehat{\ln \lambda}>\ln \widehat{k} ; \widehat{\ln \lambda}=1.028114^{\mathrm{c}}$ & $\max W=\widehat{\ln \lambda}-\hat{k}$ \\
\hline CDM & $\widehat{\ln \lambda}=\ln \hat{k}$ & $\max / \min W=\widehat{\ln \lambda}-\widehat{k}$ or $W^{\prime}=\widehat{k}-\widehat{\ln \lambda}$ \\
\hline BAU1 & $\widehat{\ln \lambda}<\ln \hat{k} ; \hat{k}=1.8092514^{\mathrm{d}}$ & $\max W^{\prime}=\hat{k}-\widehat{\ln \lambda}$ \\
\hline BAU2 & $\widehat{\ln \lambda}<\ln \hat{k} ; \hat{k}=2.6658363^{\mathrm{e}}$ & $\max W^{\prime}=\hat{k}-\widehat{\ln \lambda}$ \\
\hline BAU3 & $\widehat{\ln \lambda}<\ln \hat{k} ; \hat{k}=3.3863549^{\mathrm{f}}$ & $\max W^{\prime}=\hat{k}-\widehat{\ln \lambda}$ \\
\hline
\end{tabular}

(a) Because, as shown by Table 4, $k$ is much smaller than $\lambda$, the greater of them must be scaled down through logarithms to make them comparable. (b) Growth rate for $\lambda$ that would smooth, over 25 years (1988-2012), the accumulated deforestation reduction rate defined by a 7-year programme, from 2007 to 2015, for reducing deforestation in the Brazilian Amazon [29]. The annual reduction rates for every period $t=1, \ldots, 7$ are, respectively, 25\%, 25\%, 30\%, 40\%, $50 \%, 75 \%$ and $100 \%$. The "capitalisation" (multiplication) of all these rates yields 7.4648438 , which amounts to the full figure to be reached in 7 years. This 7-year time is factored into a 25-year period, thereby yielding 3.5714286 sub-periods, over which the deforestation reduction rate accumulated during 7 years is spread according to its geometric mean $\left(\frac{25}{7} \sqrt{7.4648438}\right)$.

(c) Growth rate for $\lambda$ that would amount to a $100 \%$ deforestation reduction in 25 years. It is calculated by $\sqrt[25]{2}$, where 2 is a rate of growth that is worth $100 \%$. (d) Value needed to yield an annual rate of economic growth of $2.40 \%$ during 25 years. This rate is the one projected for Brazil's GDP growth in 2013 by the Brazilian Central Bank, in its latest Focus Report [30]. (e) Value needed to yield an annual rate of economic growth of $4.00 \%$ during 25 years. (f) Value needed to yield an annual economic growth rate of $5.00 \%$ during 25 years.

Table 7. Scenario analysis 


\begin{tabular}{ccccccccc}
\hline Scenario & $\begin{array}{c}\hat{\varepsilon}^{*} \\
\left(\times 10^{-4}\right)\end{array}$ & $\hat{\lambda}^{*}$ & $\hat{\ln \lambda^{*}}$ & $\hat{k}^{*}$ & $\ln ^{*}$ & $\begin{array}{c}\hat{\lambda}^{*} \% \\
\text { p.a. }^{+}\end{array}$ & $\begin{array}{c}\hat{k}^{*} \% \\
\text { p.a. }{ }^{+}\end{array}$ & $\begin{array}{c}\text { Allowed def. } \\
\text { rate } \delta^{*} \% \text { p.a. } \\
(\text { Eq. }(33))\end{array}$ \\
\hline REDD1 & 1.637 & 5.7874 & $\mathbf{1 . 7 5 5 6 8 2}$ & 1.000254 & 0.000254 & 7.27520 & 0.00102 & 3.1804 \\
\hline REDD2 & 2.395 & 2.7958 & $\mathbf{1 . 0 2 8 1 1 4}$ & 1.000372 & 0.000372 & 4.19819 & 0.00149 & 6.7997 \\
\hline $\ln \lambda=\hat{k}$ & 2.453 & 2.7193 & $\mathbf{1 . 0 0 0 3 8 1}$ & $\mathbf{1 . 0 0 0 3 8 1}$ & 0.000381 & 4.08267 & 0.00153 & 6.8623 \\
\hline CDM & 2464.70 & 1.3832 & $\mathbf{0 . 3 2 4 3 6 8}$ & 1.383156 & $\mathbf{0 . 3 2 4 3 6 8}$ & $\mathbf{1 . 3 0 5 9 2}$ & $\mathbf{1 . 3 0 5 9 2}$ & 7.8350 \\
\hline BAU1 & 5205.61 & 1.3829 & 0.324176 & $\mathbf{1 . 8 0 9 2 5 1}$ & 0.592913 & 1.30515 & $\mathbf{2 . 4 0 0 0 0}$ & 7.8352 \\
\hline BAU2 & 10715.70 & 1.3828 & 0.324087 & $\mathbf{2 . 6 6 5 8 3 6}$ & 0.980518 & 1.30479 & $\mathbf{4 . 0 0 0 0 0}$ & 7.8353 \\
\hline BAU3 & 15350.53 & 1.3827 & 0.324062 & $\mathbf{3 . 3 8 6 3 5 5}$ & 1.219754 & 1.30469 & $\mathbf{5 . 0 0 0 0 0}$ & 7.8353 \\
\hline
\end{tabular}

(†) Growth rates per annum (p.a.). Figures under these column captions respectively come from $\left[\left(\sqrt[25]{\hat{\lambda}^{*}}\right)-1\right] \times 100$ and $\left[\left(2 \sqrt[5]{k^{*}}\right)-1\right] \times 100 .(\ddagger)$ Provided by GAMS-IDE 24.1.2.

Table 8. Optimal $\left(^{*}\right)$ results ${ }^{\ddagger}$ from scenario analysis

$$
\delta^{*}=\left[\sqrt[25]{\left(\lambda-\hat{\lambda}^{*}\right)}-1\right] \times 100, \text { with } \lambda>\hat{\lambda}^{*}
$$

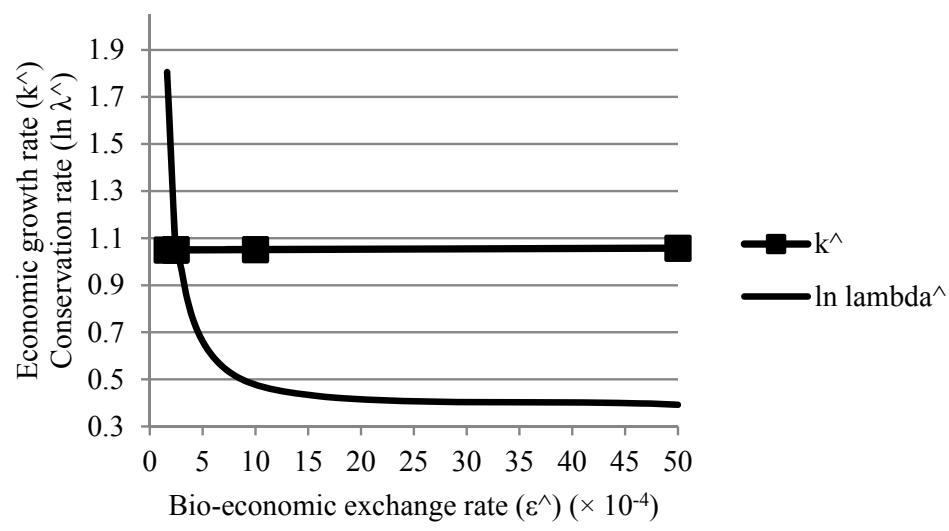

Figure 5. Aggregate equilibrium for conservation and deforestation in the Brazilian Legal Amazon

\section{Removal trade}

Now, the optimal values for $\varepsilon$ brought to light in Table 8 can be used in Table 9 to define, as in Figure 2.b, the amount of removal loans across the space $(Z)$ and over time $(M)$. Of course, this previously requires that both $Z$ and $M$ are estimated as long-run functions of $\varepsilon$. However, as shown in Table 4, it is precisely $\varepsilon$ that arises from observable $Z$ and $M$; not the other way 
around. So, what must be estimated first and foremost is an equation in which $\varepsilon$ works as a long-run function of observable $Z$ and $M$.

$$
\begin{array}{lc}
\hat{\varepsilon}(Z)= & \exp (1.428 \times Z) \\
\text { t- stat. } & 26.544 \\
\text { sig.t. } & 0.0000 \\
& \\
\hat{\varepsilon}(M)= & 6.643 M^{0.926} \\
\text { t- stat. } & 67.36435 .514 \\
\text { sig.t. } & 0.00000 .0000
\end{array}
$$

Then, the outcomes for $\hat{\varepsilon}(Z)$ and $\hat{\varepsilon}(M)$, in Eqs. (34) and (35), are used as inputs (independent

\begin{tabular}{|c|c|c|c|c|c|c|c|}
\hline Scenario & $\begin{array}{c}\hat{\varepsilon} \\
\left(\times 10^{-4}\right)\end{array}$ & $\begin{array}{c}\ln \hat{Z} \\
\left(\times 10^{2}\right)\end{array}$ & $\ln \hat{M}$ & $\begin{array}{c}\beta= \\
\ln \hat{Z}-\ln \hat{M}\end{array}$ & $\begin{array}{l}\hat{Z}(\mathrm{GtC}) \\
\text { Eq. }(36)^{\mathrm{a}}\end{array}$ & $\begin{array}{l}\hat{M}(\mathrm{GtC}) \\
\text { Eq.(37) }\end{array}$ & $\begin{array}{c}B= \\
\hat{Z}-\hat{M}\end{array}$ \\
\hline$\overline{\operatorname{Min} B}$ & 0.940 & -3.523403 & -2.114586 & -1.408817 & 0.0295 & 0.1207 & -0.0912 \\
\hline REDD1 & 1.637 & -1.642841 & -1.515764 & -0.127077 & 0.1934 & 0.2196 & -0.0262 \\
\hline$B=0$ & 1.799 & -1.413446 & -1.413446 & 0.000000 & 0.2433 & 0.2433 & 0.0000 \\
\hline REDD2 & 2.395 & -0.839176 & -1.104520 & 0.265344 & 0.4321 & 0.3314 & 0.1007 \\
\hline$\overline{\ln \lambda=\hat{k}}$ & 2.453 & -0.798110 & -1.078638 & 0.280528 & 0.4502 & 0.3401 & 0.1101 \\
\hline $\operatorname{Max} B$ & 5.454 & 0.133360 & -0.215882 & 0.349242 & 1.1427 & 0.8058 & 0.3368 \\
\hline$B=0$ & 10.621 & 0.503872 & 0.503872 & 0.000000 & 1.6551 & 1.6551 & 0.0000 \\
\hline$\overline{C D M}$ & 2464.70 & 0.893315 & 6.386668 & -5.493353 & 2.4432 & 593.87 & -591.43 \\
\hline BAU1 & 5205.61 & 0.894202 & 7.194149 & -6.299947 & 2.4454 & 1331.62 & -1329.17 \\
\hline BAU2 & 10715.70 & 0.894612 & 7.973880 & -7.079267 & 2.4464 & 2904.10 & -2901.66 \\
\hline BAU3 & 15350.53 & 0.894729 & 8.362075 & -7.467345 & 2.4467 & 4281.57 & -4279.12 \\
\hline
\end{tabular}
variables) to obtain the equations for $Z$ and $M$ as long-run functions of $\varepsilon$ :

$$
\begin{array}{lcc}
\hat{Z}(\hat{\varepsilon})=\exp \left(0.895-\frac{4.154}{\hat{\varepsilon}}\right) \\
\text { t- stat. } \quad 259.616 & -133.481 \\
\text { sig. t. } & 0.0000 & 0.0000
\end{array}
$$

$$
\begin{aligned}
& \hat{M}(\hat{\varepsilon})=0.129 \hat{\varepsilon}^{1.08} \\
& \text { t- stat. } \quad-\quad- \\
& \text { sig. t. } \quad-\quad-
\end{aligned}
$$

(a) Actually, these figures are in hundreds of GtC, so that, as indicated by Table 4, their order of magnitude can be compared to that of $M$. (b) Results provided by GAMS-IDE 24.1.2.

Table 9. Scenario analysis ${ }^{b}$ for conservation and compensation loans 


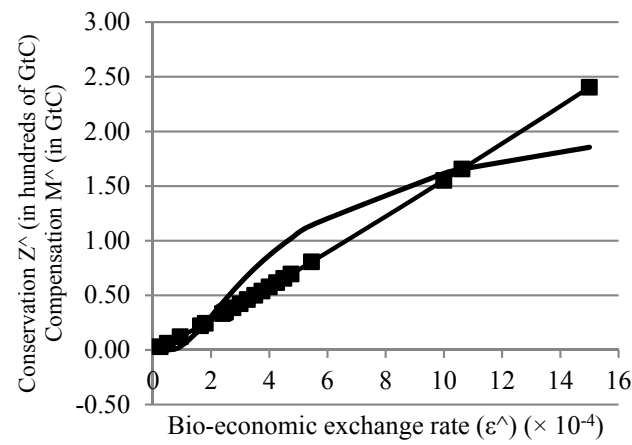

(a)

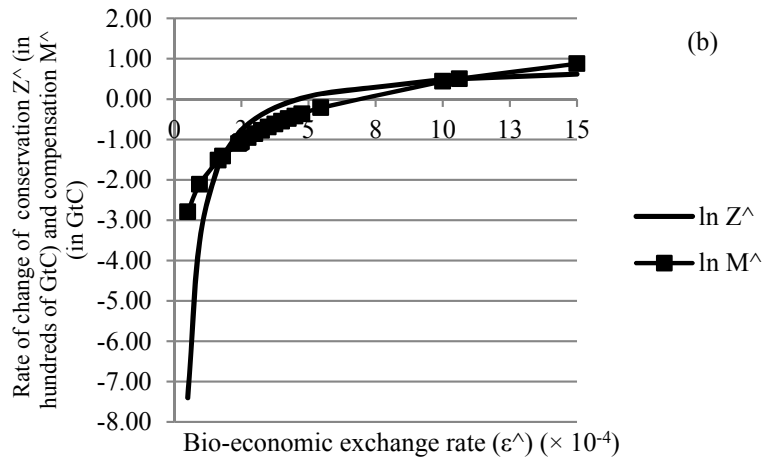

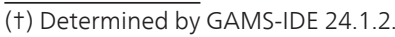

Figure 6. Optimal path ${ }^{\dagger}$ for conservation $(\hat{Z})-$ REDD - and compensation $(\hat{M})-$ CDM - loans (a) and rates $(b)$ in the long run

Eqs. (36) and (37) define, respectively, the optimal path of conservation (REDD) and compensation (CDM) to be loaned out in the long run (Figure 6.a). Since conservation is the surplus of carbon removal services, they can be exported (lent) to somewhere else. On the other hand, when these missing services have nevertheless been already used, some compensation is due. However, compensating for environmental services that were already lacking before implies importing (borrowing) them from somewhere. In this sense, conservation (exports) defines an excess supply of removal services, while compensation (imports) is caused by an excess demand for removal services. If these services are to be loaned out, the sink yielding conservation lends them, whereas the sink owing compensation borrows them.

In any event, the demand for these loans, as shown in Figure 2, lies behind disaggregate (Figure 3) - periodical - and aggregate (Figure 5) - long run - removal needs. As long as $B$ (last column of Table 9) stands for the balance of carbon trading loans, it is intere्रsting to note that a stringent scenario, such as REDD1 (Table 7), yields more ecological debt $(M)$ than ecological credit $(Z)$. This balance only turns out to be positive in the interval where $1.799 \leq \hat{\varepsilon} \leq 10.621$. $B$ reaches its maximum in this interval, when $\hat{\varepsilon}=5.454$. Later, it starts dropping, reaching zero 
again. From then on, it becomes increasingly negative, and neither the CDM nor BAU scenario can turn it over anymore.

Actually, CDM and BAU1 are but very loose scenarios. When they come into play, the ecological credit region $(1.799 \leq \hat{\varepsilon} \leq 10.621)$ has already been left behind. Therefore, in spite of the high values for $\hat{\varepsilon}$ set by CDM and BAU scenarios, these prices appear to be too low to prevent $\mathrm{B}<0$. Although $\mathrm{CDM}$ requires that $\ln \lambda=\ln k$ (Table 7 and Table 8 ), existing ecological conditions demand, rather, that $\ln \lambda>\ln k$.

If these conditions are overlooked, no further rise in $\hat{\varepsilon}$, as in the BAUs scenarios, can prevent $B$ from keep falling. That likely occurs because the environmental capacity of providing removal services has been already overshot. As it turns out, $\hat{\varepsilon}$ cannot be set like usual prices can; instead, it is set by ecological conditions, as though ecology were guiding the economy [32].

\section{Target setting}

Table 10 focuses on scenario REDD1, from Table 8, in order to demonstrate how an economy can be ecologically guided. Of course, the figures in Table 10 do not account for the real picture. Rather, they relate to a 25-year deforestation period (1988-2012), to show how things would look if it had followed out the optimal path suggested by the conservation scenario REDD1. The percentages in the last column of Table 10 were merged in such a way that the 25 -year period is divided into 7 time lags. By so doing, REDD1 reduction path, although applying to a different time period (1988-2012), can be compared to the same time length of the deforestation reduction programme tailored by [29]. The comparison is shown in Figure 7.

Nevertheless, it can still be asked why the percentage deforestation rate along the optimal path in Table 10 (15.59\%) does not match that in the last column of Table 8 (3.1804\%). Even though the former is referred to in deforested area terms, in $\mathrm{km}^{2}$, while the latter, in carbon biomass, in $\mathrm{GtC}$, the proper calculation (Eq. (39)) shows that the values would be equal. Accordingly, the percentage deforestation rates displayed in Table 10 can be reckoned either in carbon biomass $(\mathrm{GtC})$ or in area units $\left(\mathrm{km}^{2}\right)$. Actually, the underlying reason for the mismatch between deforestation rates in Table 10 and in Table 8 is that the rates in the former are bounded (Eq. (33)), whereas those in the latter are unbounded. This difference can be grasped from combining Eqs. (1) and (3) to yield:

$$
X_{t}=u_{t}+\lambda_{t} u_{t}=\left(1+\lambda_{t}\right) u_{t}
$$

From Eq. (38) and from the definition of the deforestation rate $\left(\delta_{t}\right)$ given in note $i$ of Table 10, it turns out that:

$$
\delta_{t}=\frac{u_{t}}{X_{t}}=\frac{u_{t}}{\left(1+\lambda_{t}\right) u_{t}}=\frac{1}{1+\lambda_{t}}
$$


If $\lambda_{t}$, in Eq. (39), takes on whatever optimal value displayed in Table 8, then this equation can be compared with Eq. (33). Yet now, unlike in the former equation, in the latter $\hat{\lambda}^{*}$ has an upper bound $(\lambda=7.975)$. Since this ceiling stands for a mean value for the whole period (1988-2012), it is not surprising that $\delta^{*}$ in Eq. (33) is lower than that arising from Eq. (39) - displayed in the antepenult column of Table 10.

The deforested area in Table 10 is given by Eq. (39). Its size follows closely - yet throughout a 25-year period - the size of forestland that, according to Table 3, has been cut down since $2005(t=18)$. However, while in the observed data of Table 3 , the size of deforested land keeps on getting bigger, in the optimal path of Table 10, it increasingly shrinks.

\begin{tabular}{|c|c|c|c|c|c|c|c|c|c|c|c|c|c|c|}
\hline+ & 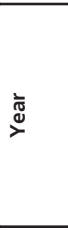 & \% & 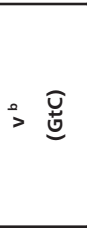 & × & N & $\begin{array}{ll}0 \\
\Sigma \\
\Sigma\end{array}$ & $\omega \frac{\bar{g}}{\frac{0}{x}}$ & $=\frac{\tilde{E}}{\tilde{z}}$ & $>\frac{\stackrel{\tilde{\tilde{E}}}{\tilde{\xi}}}{\stackrel{\tilde{O}}{E}}$ & 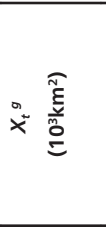 & 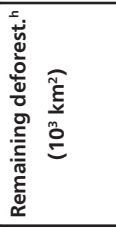 & 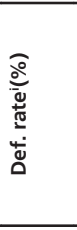 & 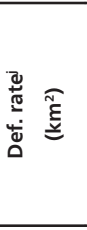 & 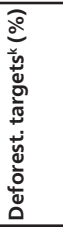 \\
\hline 1 & 1988 & 30.49 & 176.44 & 206.93 & 145.95 & 0.023890 & 1.637 & 702.46 & 3802.57 & 4505.03 & 16806.21 & 15.59 & - & 4.01 \\
\hline 2 & 1989 & 30.48 & 176.38 & 206.85 & 145.90 & 0.023881 & 1.637 & 702.21 & 3801.21 & 4503.42 & 16104.00 & 15.59 & 251.55 & 4.18 \\
\hline 3 & 1990 & 30.47 & 176.34 & 206.81 & 145.87 & 0.023877 & 1.637 & 702.07 & 3800.45 & 4502.52 & 15401.93 & 15.59 & 140.54 & 4.36 \\
\hline 4 & 1991 & 30.46 & 176.31 & 206.78 & 145.85 & 0.023873 & 1.637 & 701.96 & 3799.83 & 4501.79 & 14699.98 & 15.59 & 114.06 & 4.56 \\
\hline 5 & 1992 & 30.46 & 176.28 & 206.74 & 145.82 & 0.023868 & 1.637 & 701.82 & 3799.07 & 4500.89 & 13998.16 & 15.59 & 140.54 & 4.77 \\
\hline 6 & 1993 & 30.46 & 176.28 & 206.74 & 145.82 & 0.023868 & 1.637 & 701.82 & 3799.07 & 4500.89 & 13296.35 & 15.59 & 0.00 & 5.01 \\
\hline 7 & 1994 & 30.45 & 176.20 & 206.65 & 145.76 & 0.023858 & 1.637 & 701.51 & 3797.43 & 4498.94 & 12594.83 & 15.59 & 303.49 & 5.28 \\
\hline 8 & 1995 & 30.43 & 176.13 & 206.57 & 145.70 & 0.023848 & 1.637 & 701.24 & 3795.93 & 4497.17 & 11893.60 & 15.59 & 275.99 & 5.57 \\
\hline 9 & 1996 & 30.42 & 176.08 & 206.51 & 145.66 & 0.023841 & 1.637 & 701.03 & 3794.83 & 4495.86 & 11192.57 & 15.59 & 203.68 & 5.89 \\
\hline 10 & 1997 & 30.42 & 176.05 & 206.47 & 145.63 & 0.023837 & 1.637 & 700.90 & 3794.12 & 4495.02 & 10491.67 & 15.59 & 132.40 & 6.26 \\
\hline 11 & 1998 & 30.41 & 176.00 & 206.41 & 145.59 & 0.023831 & 1.637 & 700.72 & 3793.16 & 4493.88 & 9790.94 & 15.59 & 177.03 & 6.68 \\
\hline 12 & 1999 & 30.40 & 175.96 & 206.36 & 145.55 & 0.023825 & 1.637 & 700.55 & 3792.21 & 4492.75 & 9090.40 & 15.59 & 175.77 & 7.16 \\
\hline 13 & 2000 & 30.40 & 175.91 & 206.31 & 145.52 & 0.023818 & 1.637 & 700.36 & 3791.20 & 4491.56 & 8390.04 & 15.59 & 185.62 & 7.70 \\
\hline 14 & 2001 & 30.39 & 175.87 & 206.25 & 145.48 & 0.023812 & 1.637 & 700.18 & 3790.20 & 4490.38 & 7689.86 & 15.59 & 185.00 & 8.35 \\
\hline 15 & 2002 & 30.38 & 175.81 & 206.19 & 145.43 & 0.023805 & 1.637 & 699.96 & 3789.02 & 4488.98 & 6989.90 & 15.59 & 217.88 & 9.10 \\
\hline 16 & 2003 & 30.37 & 175.75 & 206.11 & 145.38 & 0.023796 & 1.637 & 699.70 & 3787.63 & 4487.33 & 6290.20 & 15.59 & 257.12 & 10.01 \\
\hline 17 & 2004 & 30.35 & 175.68 & 206.03 & 145.32 & 0.023786 & 1.637 & 699.42 & 3786.12 & 4485.54 & 5590.78 & 15.59 & 279.28 & 11.12 \\
\hline 18 & 2005 & 30.35 & 175.63 & 205.97 & 145.28 & 0.023780 & 1.637 & 699.23 & 3785.08 & 4484.31 & 4891.55 & 15.59 & 191.93 & 12.51 \\
\hline 19 & 2006 & 30.34 & 175.59 & 205.93 & 145.25 & 0.023775 & 1.637 & 699.09 & 3784.30 & 4483.39 & 4192.46 & 15.59 & 143.69 & 14.29 \\
\hline 20 & 2007 & 30.34 & 175.56 & 205.90 & 145.23 & 0.023771 & 1.637 & 698.97 & 3783.66 & 4482.63 & 3493.49 & 15.59 & 117.44 & 16.67 \\
\hline 21 & 2008 & 30.33 & 175.53 & 205.86 & 145.20 & 0.023767 & 1.637 & 698.84 & 3782.95 & 4481.79 & 2794.65 & 15.59 & 131.49 & 20.00 \\
\hline 22 & 2009 & 30.33 & 175.51 & 205.84 & 145.18 & 0.023764 & 1.637 & 698.76 & 3782.54 & 4481.30 & 2095.89 & 15.59 & 76.02 & 25.00 \\
\hline 23 & 2010 & 30.32 & 175.49 & 205.82 & 145.17 & 0.023762 & 1.637 & 698.69 & 3782.15 & 4480.84 & 1397.20 & 15.59 & 71.29 & 33.34 \\
\hline
\end{tabular}




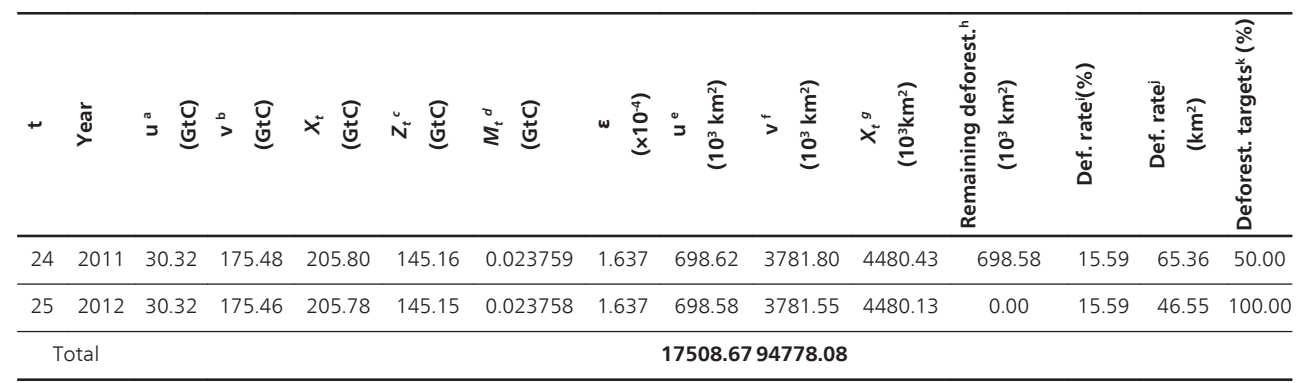

(a) $u_{t}=X_{t} \div\left(1+\hat{\lambda}^{*}\right)$. (b) $v_{t}=X_{t}-u_{t}$. (c) Eq. (2). (d) Eq. (14): $M_{t}=\varepsilon \times Z_{t^{t}}$ (e) $\left(u_{t} \div 434\right) \times 10^{-4}$, according to note e in Table 3. (f) $\left(v_{t} \div 464\right) \times 10^{-4}$, according to note $d$ in Table 3. (g) $X_{t}\left(\right.$ in $\left.\mathrm{km}^{2}\right)=u_{t}\left(\right.$ in $\left.\mathrm{km}^{2}\right)+v_{t}$ (in $\left.\mathrm{km}^{2}\right)$. However unrealistic it may sound, the total area "shrinks" to account for the loss of forestland implied by substituting the carbon stored in deforested sites for that stored in natural forests. (h) For $t=1$ (1988), $\Sigma_{t} u_{t}$ (in km²) $=17508.67-u_{1}$ (in km²); for $t>1$, (remaining deforestation) $)_{t-1}-u_{t}$ (in km²). (i) $u_{t}\left(\right.$ in $\left.\mathrm{km}^{2}\right) \div X_{t}$ (in $\left.\mathrm{km}^{2}\right)$. (j) $\left(u_{t-1}-u_{t}\right.$ ) (in $\left.\mathrm{km}^{2}\right) \times 10^{3}$. (k) For $t=1(1988), u_{t}\left(\right.$ in $\left.\mathrm{km}^{2}\right) \div \Sigma_{t} u_{t}\left(\right.$ in $\left.\mathrm{km}^{2}\right)$; for $t>1, u_{t}\left(\right.$ in $\left.\mathrm{km}^{2}\right) \div(\text { remaining deforestation })_{t-1}$.

Table 10. Deforestation targets and rates from optimal results in the REDD1 scenario $\left(\hat{\lambda}^{*}=5.7874\right)$ (Table 8)

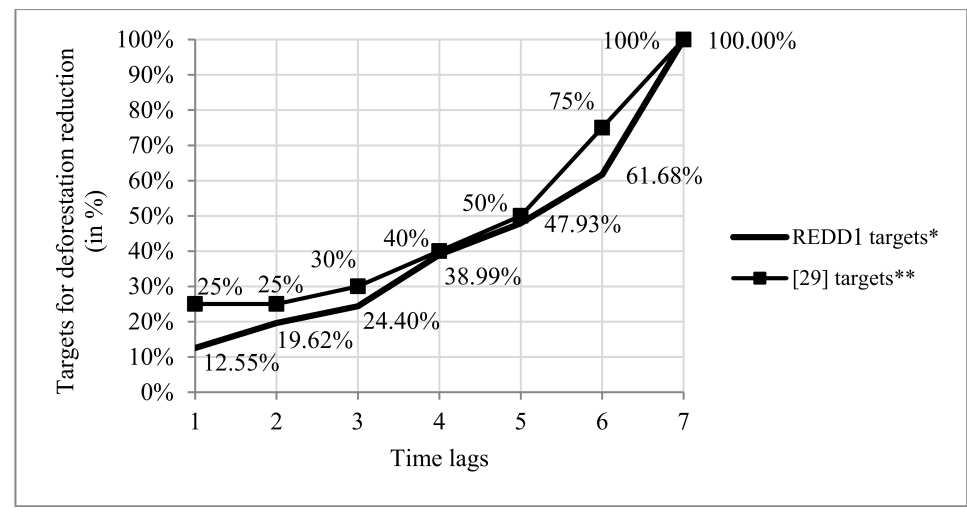

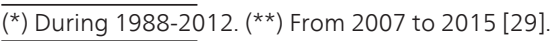

Figure 7. Targets for reducing deforestation in the Brazilian Legal Amazon

\section{Conclusion}

The analysis carried out so far has demonstrated that, where policy climate and deforestation are concerned, carbon conservation (REDD) and compensation (CDM) entail a trade-off that cannot be overcome by monetary mechanisms. Instead of money, the underlying variable which forest value rests upon is the bio-diversity ratio $(\lambda)$. Although it is typically a spacebased measure, this ratio also accounts for forestland distribution over time. When $\lambda$ is affected by the demand of removal stocks $(h)$ set off by the emissions growth from the economy, the 
amount of compensation $(M)$ for these emissions over time is assumed to feed on the conservation $(Z)$ of carbon savings carried out at each period.

Conservation surplus can be loaned out to afford compensation demands from an economy producing growing emissions. However, such demands must be halted somewhere, otherwise the supply of removal forest stocks $\left(G\left(X_{t}\right)\right)$ will hit a ceiling and fall short of delivering enough conservation. As shown by Figure 6 and Table 9, it is likely there also is a biophysical limit to conservation, which should prevent this environmental service from being further encouraged by incentives such as monetary payments (PES). When conservation is driven too far, as in the REDD1 scenario (Table 8 and Table 9), it might end up turning the balance of carbon trading loans negative. On the other hand, when it is traded off against compensation, as in the CDM scenario, it deteriorates the balance of carbon trading loans even further. Quite often, economywise price setting and policy-making grow apart from ecological conditions.

Figure 2, Figure 3, Figure 5 and Figure 6 show how ecology could economically guide the economy [32]. If this linkage should be fully accomplished, setting targets for reducing deforestation would be grounded in biophysical, rather than in economic or political bearings.

Shifting from a deforestation avoidance approach to a forest stock maintenance one would certainly be a step forward. While the former carries a misleadingly uneconomic meaning, the latter brings forest conservation to the economic foreground. As avoiding deforestation usually implies forgoing profit-making activities, it mistakenly underlies monetary rewards. Thus, a great deal of the REDD mechanism draws heavily upon them. However, from a bioeconomic standpoint, they are most likely to become romantic red roses, whose purchase will, rather than mend a broken heart, make money melt into thin air.

\section{Author details}

Valny Giacomelli Sobrinho*

Address all correspondence to: giacomelliv@yahoo.com.br

Department of Economics, Federal University of Santa Maria (UFSM), Santa Maria, Rio Grande do Sul, Brazil

\section{References}

[1] Linhares-Juvenal T. REDD and the Challenge of Protecting the Global Forest Cover. In: Serôa da Motta R., Hargrave J., Luedemann G., Gutierrez MBS. (eds.) Climate Change in Brazil - Economic, Social and Regulatory Aspects. Brasília: IPEA; 2011. p319-328. 
[2] Kanninen M., Murdiyarso D., Seymour F, Angelsen A., Wunder S., German L. Do Trees Grow on Money? The Implications of Deforestation Research for Policies to Promote REDD. Bogor, Indonesia: CIFOR; 2007.

[3] Giacomelli Sobrinho V. Carbon Bio-Economics and Forests - Getting the BESF out of Climate Policy. In: Kheradmand H. (ed.) Climate Change - Socioeconomic Effects. Rijeka: InTech; 2011. p401-424.

[4] Martin RM. Deforestation, Land-Use Change and REDD. Unasylva 2008; 59(230): 3-11.

[5] Angelsen A., editor. Analyzing REDD+ - Challenges and Choices. Bogor, Indonesia: CIFOR; 2012.

[6] Polanyi K. A Grande Transformação - As Origens de Nossa Época. Rio de Janeiro: Campus; 2000.

[7] Whiteman A. Money Doesn't Grow on Trees: A Perspective on Prospects for Making Forestry Pay. Unasylva 2003; 54(212): 3-10.

[8] Prince's Charities' International Sustainability Unit. Interim REDD+ Finance - Current Status and Ways Forward for 2013-2000. London: The Prince of Wales' Charitable Foundation; 2012. http://www.pcfisu.org/the-princes-rainforests-project/interimredd-finance (accessed 8 September 2013).

[9] Daly HE., Farley, J. Economia Ecológica - Princípios e Aplicações. Lisboa: Instituto Piaget; 2004.

[10] Soddy F. The Rôle of Money - What It Should Be, Contrasted with What It Has Become. London: Routledge; 1934.

[11] Tobin J. Money. In: Durlauf SN., Blume LE. (eds.) Monetary Economics. 2nd. ed. Hampshire, UK: Palgrave Macmillan; 2010. p224-241.

[12] Instituto do Homem e Meio Ambiente da Amazônia. IMAZON: Mapas: Desmatamento Acumulado na Amazônia Legal 2007-2012: Desmatamento na Amazônia Legal até 2012. http:// www.imazon.org.br/mapas/desmatamentoacumulado-2007-2010/desmatamento-amazonia-legal-acumulado-ate-2012/view (accessed 25 September 2013).

[13] Georgescu-Roegen N. Entropy, Value, and Development. In: Georgescu-Roegen N. The Entropy Law and the Economic Process. Cambridge, US, London, UK: Harvard University Press; 1999. p276-315.

[14] Faucheux S., Noël JF. Economia dos Recursos Naturais e do Meio Ambiente. Lisboa: Instituto Piaget; 1995.

[15] Ayres RU. On the Life Cycle Metaphor: Where Ecology and Economics Diverge. Ecological Economics 2004; 48: 425-438. 
[16] Costanza R. Value Theory and Energy. Encyclopedia of Energy 2004; 6: 337-346.

[17] Pearce D., Moran D. O Valor Económico da Biodiversidade. Lisboa: Instituto Piaget; 1994.

[18] Daly HE. The Economics of the Steady State. The American Economic Review 1974; 64: 15-21.

[19] Clark CW. Mathematical Bio-Economics - the Mathematics of Conservation. 3rd. ed. Hoboken, US: John Wiley \& Sons; 2010.

[20] Wackernagel M., Rees W. Our Ecological Footprint - Reducing Human Impact on the Earth. Gabriola Island, Canada: New Society Publishers; 1996.

[21] Fearnside PM. Forests and Global Warming Mitigation in Brazil: Opportunities in the Brazilian Forest Sector for Responses to Global Warming under the "Clean Development Mechanism". Biomass and Bioenergy 1999; 16: 171-189.

[22] Fearnside PM. Greenhouse Gases from Deforestation in Brazilian Amazonia: Net Committed Emissions. Climatic Change 1997; 35: 321-360.

[23] Instituto Nacional de Pesquisas Espaciais. INPE: Amazonia: PRODES: Taxas Anuais 1988 a 2012. http://www.obt.inpe.br/prodes/prodes_1988_2012.htm (accessed 20 September 2013).

[24] Common M. Environmental and Resource Economics - an Introduction. 2nd. ed. New York: Addison Wesley Longman; 1996.

[25] Ayres RU. The Second Law, the Fourth Law, Recycling and Limits to Growth. Ecological Economics 1999; 29: 473-483.

[26] Houthakker HS. The Permanent Income Hypothesis. The American Economic Review 1958; 48: 396-404.

[27] Meghir C. A Retrospective on Friedman's Theory of Permanent Income. The Economic Journal 2004; 114: F293-F306.

[28] Perman R., Ma Y., McGilvray J., Common M. Natural Resource and Environmental Economics. 3rd. ed. Harlow, England: Pearson Education; 2003. http://rapidlibrary.com/files/ perman-natural-resource-and-environ mental-economics-3rd-edition-pdf_ulczebmccni89on.html (accessed 19 November 2012).

[29] Instituto Socioambiental. ISA, Greenpeace, Instituto Centro de Vida. ICV, The Nature Conservancy. TNT, Conservação Internacional, Amigos da Terra - Amazônia Brasileira, Instituto do Homem e Meio Ambiente na Amazônia. IMAZON, WWF-Brasil. Pacto pela Valorização da Floresta e pelo Fim do Desmatamento na Amazônia Brasileira. http://www.socioambiental. org/banco_imagens/pdfs/doc-pacto\%20desmatamento\%20zero\%20SUM\%20ONGs\%20FINAL. pdf (accessed 25 September 2013) 
[30] Banco Central do Brasil. BCB. Sistema de Metas para a Inflação: Sala do Investidor: Focus: Focus - Relatório de Mercado. http://www.bcb.gov.br/pec/GCI/PORT/readout/R20130920.pdf (accessed 25 September 2013).

[31] Martins H., Fonseca A., Souza Jr. C., Sales M., Veríssimo A. Boletim do Desmatamento (SAD) Agosto de 2013. Boletim Transparência Florestal da Amazônia Legal 2013: 12. http://www. imazon.org.br/publicacoes/transparencia-florestal/transparenciaflorestal-amazonia-legal/boletim-do-desmatamento-sad-agosto-de-2013-1 (accessed 25 September 2013).

[32] Giacomelli Sobrinho V. Bio-economics and ecosystem services: how ecology can economically guide the economy. In: Bürgi M. (ed.) Frontiers in Historical Ecology: Abstracts: proceedings of the International Conference of the International Union of Forest Research Organisations (IUFRO), Swiss Federal Institute for Forest, Snow and Landscape Research (WSL), 27 August - 2 September 2011, Birmensdorf, Switzerland. Birmensdorf: WSL; 2011. http://www.wsl.ch/ publikationen/pdf/11114.pdf 
